\title{
THE ROLE OF SUBSTITUENTS IN THE HERON REACTION OF ANOMERIC AMIDES
}

\begin{tabular}{|r|l|}
\hline Journal: & Canadian Journal of Chemistry \\
\hline Manuscript ID & cjc-2016-0300.R1 \\
\hline Manuscript Type: & Article \\
\hline Date Submitted by the Author: & 28 -Jul-2016 \\
\hline Complete List of Authors: & $\begin{array}{l}\text { Glover, Stephen; University of New England School of Science and } \\
\text { Technology, Chemistry } \\
\text { Rosser, Adam; University of New England School of Science and } \\
\text { Technology, Chemistry }\end{array}$ \\
\hline Keyword: & $\begin{array}{l}\text { Anomeric Effects, HERON reaction, Anomeric amides, Diminshed amide } \\
\text { resonance, pyramidal amides }\end{array}$ \\
\hline
\end{tabular}

SCHOLARONE $^{\text {m }}$

Manuscripts 
The Role of Substituents in the HERON ReACtion OF ANOMERIC AMIDES

Stephen A. Glover ${ }^{1 *}$ and Adam A. Rosser

*School of Science and Technology, University of New England, Armidale, New South Wales 2350, Australia.

${ }^{1}$ Corresponding author.

Tel: 610458752202

Fax:61 267733268

Email:sglover@une.edu.au 


\begin{abstract}
Anomeric amides, $\mathrm{RCON}(\mathrm{X})(\mathrm{Y})$, have two electronegative atoms at the amide nitrogen, a configuration that results in greatly reduced amide resonance and strongly pyramidal nitrogen atoms. This, combined with facilitation of anomeric interactions, can result in the HERON reaction, an intramolecular migration of the more electronegative atom, $X$, from nitrogen to the carbonyl with production of a $Y$-stabilised nitrene. We have modelled, at B3LYP/6-31G(d) level, a variety of anomeric amides that undergo the HERON reaction to determine factors that underpin the process. The overriding driving force is anomeric destabilisation of the bond to the migrating group. Rotated transition states show loss of residual resonance and this is a component of the overall activation energies. However, the reduced resonance in these systems plays only a minor role. We have determined the resonance energies (RE) and HERON activation barriers, $E_{\mathrm{A}}$, of five anomeric systems. RE for the amides have been calculated isodesmically using our calibrated trans amidation method and COSNAR calculations. Reduction of their overall $E_{\mathrm{A}}$ 's by the corresponding RE gives rearrangement energies, $E_{\text {rearr. }}$, a measure of relative impact on rearrangement of substituents on nitrogen. In $\mathrm{CH}_{3} \mathrm{CON}(\mathrm{OMe})(\mathrm{Y})$ systems producing $\left(\mathrm{CH}_{3} \mathrm{CO}_{2} \mathrm{Me}+\mathrm{NY}\right)$, a loosely-bound electron pair on the donor atom, $Y$, in $\mathrm{n}_{\mathrm{Y}}-\sigma^{*}{ }_{\text {NOMe }}$ anomeric interactions drives the reaction. $E_{\text {rearr. }}$ increases in the sequence $Y=N($ nitrene $)<O^{-}$(oxide) $<<N M e_{2}<S M e<<O M e$. For the same systems, RE increases in the order $Y=N<O^{-}<<\mathrm{OMe}<<\mathrm{NMe}_{2} \sim \mathrm{SMe}$. Other effects such as molecular conformation, nature of the migrating group, $X$, as well as acyl substituents at the carbonyl carbon are discussed.
\end{abstract}

Keywords: anomeric amides, HERON reactions; reaction mechanism; pyramidal amides; amide resonance;anomeric effects 


\section{Introduction}

In the course of our investigations into the biological activity of a class of direct-acting mutagens, $N$-acyloxy- $N$-alkoxyamides 1a, we have encountered a range of unusual amides, so-called anomeric amides, which are amides bearing two electronegative atoms at the nitrogen $\mathbf{1}$. Much has now been published concerning the unusual properties of such amides. ${ }^{1-12}$ The combined electronegativity of $X$ and $Y$ results in a high degree of pyramidalisation of the amide nitrogen resulting in localisation of the nitrogen lone pair in an $\mathrm{sp}^{3}$ hybrid orbital rather than the normal $2 \mathrm{p}_{z}$ orbital. The energy of the lone pair is also lowered resulting in a diminution of the degree of resonance over the amide carbonyl with attendant lengthening of the $N-C(O)$ bond and much higher carbonyl stretch frequencies in their IR spectra, the latter due to higher pi bond character through destabilisation of the polar, single bond resonance form of the carbonyl. In addition, x-ray structural data and theoretical calculations on the ground state structures demonstrate pronounced $\mathrm{n}_{\mathrm{Y}}-\mathrm{\sigma}^{*}{ }_{\mathrm{NX}}$ anomeric effects through the central amide nitrogen.<smiles>[R]C(=O)N([X])[X]</smiles>

1<smiles>CN(C)C=O</smiles>

2<smiles>[R]ON(C([R])=O)N([R7])C([R])=O</smiles>

3

a: $\mathrm{X}=\mathrm{O}_{2} \mathrm{CR}, \mathrm{Y}=\mathrm{OR}$

b: $X=\mathrm{OR}, \mathrm{Y}=\mathrm{NR}_{2}$

c: $X=\mathrm{OR}, \mathrm{Y}=\mathrm{OH}^{2}$

d: $X=O R, Y=O^{-}$

e: $X=O R, Y=S R$

f: $\mathrm{X}=\mathrm{Cl}, \mathrm{Y}=\mathrm{OR}$

g: $X=\mathrm{OR}, Y=\mathrm{N}_{3}$

h: $X=O R, Y=N$

i: $X=Y=O R$

Not only are there structural and spectroscopic changes, these amides undergo a variety of reactions that are not found in normal $N, N$-dialkyl, $N$-alkyl- or primary amides. With suitable substituents that can stabilise negative charge, both $\mathrm{S}_{\mathrm{N}} 1$ and $\mathrm{S}_{\mathrm{N}} 2$ reactions at nitrogen have been shown to occur. For instance, $N$-acyloxy- $N$-alkoxyamides 1a undergo $\mathrm{S}_{\mathrm{N}} 2$ reactions with arylamines to generate $N$ amino- $\mathrm{N}$-alkoxyamides $\mathbf{1 b},{ }^{7,8,13-16}$ reaction in base to give hydroxamic acids $\mathbf{1 c},{ }^{17}$ which convert to 
their anions 1d, and reaction with thiols to generate intermediate $N$-alkoxy- $N$-alkylthiylamides 1e. ${ }^{18}$ With aqueous acid catalysis they are hydrolysed to $N$-alkoxyhydroxamic acids $1 \mathrm{c}$ and carboxylic acids in $\mathrm{A}_{\mathrm{Al}} 1$ reactions. ${ }^{19,20}$ Both $N$-acyloxy- $N$-alkoxyamides 1a and $N$-alkoxy- $N$-chloroamides $\mathbf{1 f}$ undergo $\mathrm{S}_{\mathrm{N}} 2$ reactions with azide to give $N$-alkoxy- $N$-azidoamides $\mathbf{1 g}$, which decompose to $N$-acyl$\mathrm{N}$-alkoxyaminonitrenes (1-acyl-1-alkoxydiazenes) $\mathbf{1 h}$ and nitrogen. ${ }^{21} \mathrm{~N}$-Acyloxy- $\mathrm{N}$-alkoxyamides 1a themselves are formed by $S_{N} 2$ displacement of chlorine in $\mathbf{1 f}$ by carboxylates. ${ }^{16,17,22}$ Solvolysis of $N$-alkoxy- $N$-chloroamides $\mathbf{1 f}$ in aqueous alcohol can generate $N, N$-dialkoxyamides $\mathbf{1 i}{ }^{23}$ which can also be generated directly from hydroxamic esters with phenyliodine bis(trifluoroacetate) (PIFA) in appropriate alcohols. ${ }^{10} \mathrm{~N}$-Alkoxy- $N$-chloroamides $\mathbf{1 f}$ react with Lewis acids yielding $N$ acyl- $N$-alkoxynitrenium ions, a reaction that has proven to be useful in the intramolecular addition of such ions to olefins and aryl systems..$^{24-31}$ Similar structural properties and reactions of the related anomeric carbamates and ureas have been studied extensively by Shtamburg and coworkers. $^{32-38}$

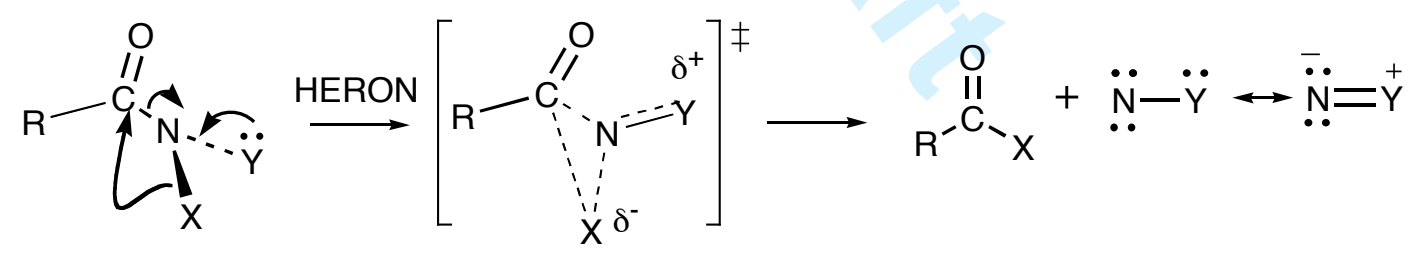

Scheme 1

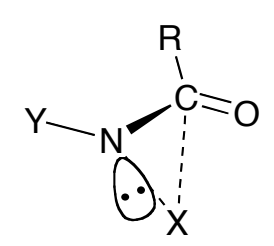

(a)

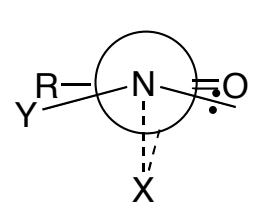

(b)

Fig. 1. Theoretically derived transition state for the generalised HERON reaction of an $X, Y$ substituted amide; (a) perspective drawing, (b) Newman projection along the $N-C(O)$ bond. 
Anomeric amides have also been found to undergo an unusual intramolecular rearrangement, now known as the HERON reaction (Heteroatom Rearrangements $\boldsymbol{O}$ n Nitrogen), which was first implicated in the reactions of $N$-acyloxy- $N$-alkoxyamides $1 a$ with $N$-methylaniline and in which the intermediate $N$-alkoxy- $N$-methylanilinoamides $\mathbf{1 b}$ generate esters together with 1,1-diazenes (Scheme 1, $\mathrm{Y}=\mathrm{NMePh}, \mathrm{X}=\mathrm{OR})^{7,8,13,14,39-41}$ Notably, the process in this case is facilitated by a strong $\mathrm{n}_{\mathrm{N}}-\sigma^{*}{ }_{\text {NOR }}$ anomeric interaction between the nitrogen substituents, which weakens the $N-$ $O R$ bond resulting in its migration from nitrogen to the carbonyl carbon concomitant with $N-C(O)$ bond heterolysis. Theoretical evaluation of the rearrangement for model 2 at B3LYP/6-31G(d) level predicted a modest $E_{\mathrm{A}}$ of $\sim 20 \mathrm{kcal} \mathrm{mol}^{-1}$ and a transition state in which the lone pair on nitrogen resides in the $N-C(O)$ plane and all resonance is lost. ${ }^{40}$ In addition, the alkoxyl group migrates in a plane orthogonal to the $N-C(O)$ plane (Fig. 1a and Fig. 1b, $\mathrm{Y}=\mathrm{NR}_{2}, \mathrm{X}=\mathrm{OR}$ ). The reaction was also studied directly in the thermal decomposition of $N, N^{\prime}$-dialkoxy- $N, N^{\prime}$-diacylhydrazines $\mathbf{3}$, which decompose near room temperature and with $E_{\mathrm{A}}{ }^{\prime} \mathrm{s}$ of $20-30 \mathrm{kcal} \mathrm{mol}^{-1}$ in consecutive three-centre HERON processes giving two equivalents of ester and nitrogen; 1-acyl-1-alkoxydiazenes $\mathbf{1 h}$ are intermediates. ${ }^{40}$<smiles>CCOC(=O)N(OCC)OC(C)=O</smiles>

4<smiles></smiles>

5

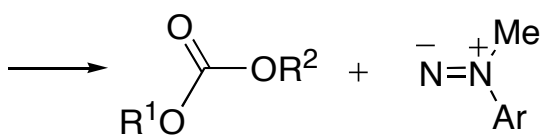

6

Scheme 2<smiles></smiles>

$1 a$<smiles>[R]C(=O)OC([R])=O</smiles>

8<smiles>[18O]N[18O]</smiles>

9

Scheme 3 


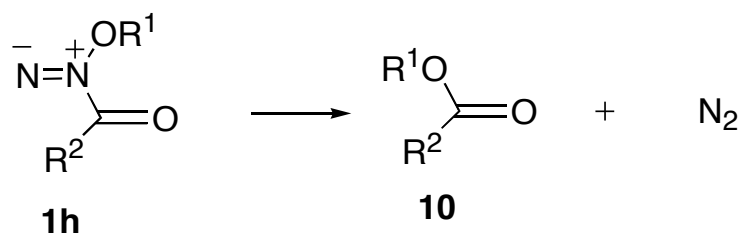

Scheme 4

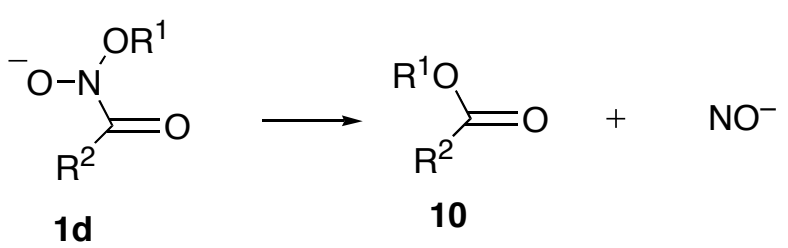

Scheme 5

Other systems undergo the HERON reaction. $N$-Acyloxy- $N$-alkoxycarbamates 4 also react at room temperature with $N$-methylaniline to form $N$-alkoxy- $N$-methylanilinocarbamates $\mathbf{5}$, which rearrange to dialkyl carbonates $\mathbf{6}$ and the 1-methyl-1-diazene 7 (Scheme 2). ${ }^{42} \mathrm{~N}$-Acyloxy- $\mathrm{N}$-alkoxyamides $\mathbf{1 a}$ themselves generate anhydrides and alkoxynitrenes but at significantly higher temperatures in toluene (Scheme 3). ${ }^{43} \quad N$-Acyl- $N$-alkoxy-1,1-diazenes extrude nitrogen to give esters in a facile reaction which resembles the HERON process (Scheme 4), $5,21,40,44,45$ and the conjugate anions of $N$ alkoxyhydroxamic esters $\mathbf{1 d}$ readily form esters intramolecularly by a similar process (Scheme 5$).{ }^{17}$ Aminonitrenes (7, Scheme 2) and nitrogen (Scheme 4) are generated as singlets, but alkoxynitrenes (9, Scheme 3) and $\mathrm{NO}^{-}$(Scheme 5) must relax upon formation to their more stable triplet states. The features of these reactions have been highlighted in a series of papers from our laboratory and the HERON reaction has been reviewed in this journal. ${ }^{41}$

In contrast, rather than undergoing HERON reactions, $N$-alkoxy- $N$-alkylthiylamides 1 e, formed from $N$-acyloxy- $N$-alkoxyamides 1a and thiols (including glutathione) generate hydroxamic esters 11 and disulfides 12 (Scheme 6). ${ }^{18} N, N$-Dialkoxyamides 1i, instead, undergo thermolysis reactions 
in toluene generating $\mathrm{N}$-alkoxyamidyl radicals, ${ }^{10}$ while several cyclic forms rearrange by HERON reactions. $^{11}$

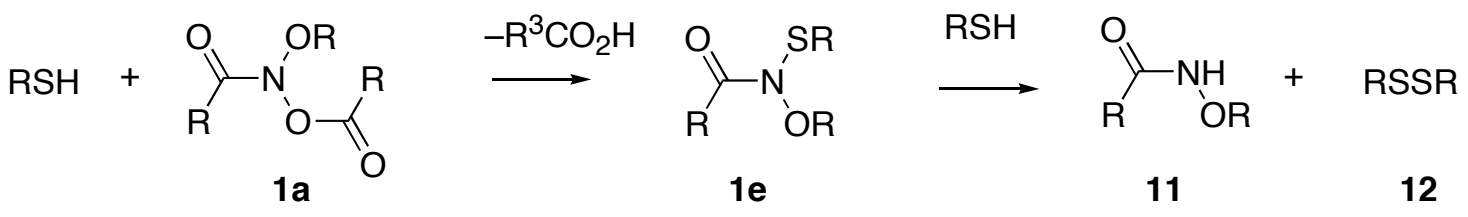

Scheme 6

From theoretical modelling, the transition states for all HERON reactions studied to date are similar to that calculated for $\mathbf{1 b}$ in that the migrating group in each case moves in a plane orthogonal to the $N-C(O)$ system and there is loss of all intrinsic resonance, with the amide nitrogen lone pair in the $N-C(O)$ plane (Scheme 1, Fig. 1). ${ }^{11,39,40,46}$

A number of factors could influence the ease of HERON reactions:

1. The strength of the anomeric destabilising effect and therefore the nature of $X$ and $Y$;

2. The degree of residual amide resonance in $\mathbf{1}$, which varies with substituents $X$ and $Y$ and, since this is sacrificed at the HERON transition state, it can also dictate the overall $E_{\mathrm{A}}$ for the process;

3. The nature of the migrating group, $X$;

4. The nature of amide acyl substituents, $\mathrm{R}$;

5. Conformation and stereoelectronic effects.

We recently showed computationally that for $N$-methoxy- $N$-dimethylaminoacetamide $\mathbf{1 3 f}$ and $N, N$ dimethoxyacetamide $\mathbf{1 3 g}$, models for $\mathbf{1 b}$ and $\mathbf{1 i}$ respectively, deconvolution of the $E_{\mathrm{A}}$ into a resonance energy $(\mathrm{RE})$ and a rearrangement energy component $\left(E_{\text {rearr }}\right)$ is possible since the residual resonance in anomeric and many other amides and lactams can be computed by trans amidation, ${ }^{47}$ and COSNAR (carbonyl substitution, nitrogen atom replacement) isodesmic studies. ${ }^{48-50} \mathrm{~N}, N$ Dimethoxyacetamide $\mathbf{1 3 g}$, with an $E_{\mathrm{A}}$ for HERON of $37.4 \mathrm{kcal} \mathrm{mol}^{-1}$, has a low residual resonance 
energy $\left(\mathrm{RE}=-8.6 \mathrm{kcal} \mathrm{mol}^{-1}\right)$ but a large rearrangement component $\left(E_{\text {rearr }}=28.8 \mathrm{kcal} \mathrm{mol}^{-1}\right)$, while 13f has a much greater degree of resonance on account of the lower combined electronegativity of the nitrogen substituents $\left(\mathrm{RE}=-12.5 \mathrm{kcal} \mathrm{mol}^{-1}\right)$ but a much lower rearrangement component $\left(E_{\text {rearr }}\right.$ $=10.4 \mathrm{kcal} \mathrm{mol}^{-1}$ ) and consequently a much lower overall $E_{\mathrm{A}}$ of $22.7 \mathrm{kcal} \mathrm{mol}^{-1} .^{46} \mathrm{In}$ this comparison it is clear that the factors affecting the ease of the migration are more important than reduced resonance.

In this paper we have examined models for HERON reactions in Scheme 2-Scheme 5 as well as possible HERON reactivity of the $N$-alkoxy- $N$-alkylthiylamides 1e to discern the relative influences of structure on the process.

\section{Computational Methods}

Fully optimised ground states of models of all structures 13a-d and 22, components used in calculation of trans amidation and COSNAR resonance energies according to eq. [1-6] and eq. [811], and transition states for HERON reactions of 13a-d and 22 were computed at the B3LYP/631G(d) level using MacSpartan 10. ${ }^{51}$ B3LYP/6-31G(d) has been shown to perform well in determinations of structure and properties of a wide range of amides, lactams and anomeric amides, 1, 3, 9,11, 12, 40,41, 46, 47 and resonance energies at this level have been demonstrated to be in relatively good agreement with those obtained with much larger basis sets and higher levels of correlation energy corrections. ${ }^{47}$ Neither model $\mathbf{1 3 e}$, nor some elements required in the computation of its resonance energy were stationary points at B3LYP/6-31G(d). Calculations at B3LYP/631G(d,p) up to B3LYP/6-311++G(d,p) and employing dispersion-corrected M06/6-311++G(d,p) on 13e ground state failed to resolve this problem. Resonance energy and HERON reaction data for 13e were computed at the HF/6-31G(d) level, which performed well with these anions. Energies of model structures in isodesmic eq. [1-6] and eq. [8-11] were computed without ZPE and thermal 
corrections since these largely cancel. Lowest energy twisted amides used in eq. [6] were obtained by transition state searches starting with a twisted form or were constrained to keep the lone pair in the $N-C(O)$ plane. Geometries of reactants, transition states and products as well as absolute energies for all components in these equations are provided as supplementary material. For the HERON reactions of $\mathbf{1 3 a - e}$ and for $\mathbf{2 2}$, the determination of activation energies and reaction energies with ZPE, and enthalpic corrections required full frequency calculations on all reactants, transition states and products. Transition states for HERON processes possessed one imaginary frequency and geometry optimisations at start and finish coordinates of the imaginary vibrational mode were carried out to ensure transition states were real and relaxed back to reactants before, and products after the transition state complex. Priority groups at nitrogen as determined according to the Cahn-Ingold-Prelog system are designated syn or anti to the carbonyl oxygen with respect to the $N-C(O)$ bond. In hydroxamate $\mathbf{1 3 e}, O^{-}$is by definition prioritised over OMe. 


\section{Results and discussion}

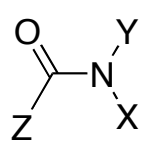

13

a: $X=O A c, Y=O M e, Z=M e$

b: $X=\mathrm{OMe}, Y=S M e, Z=\mathrm{Me}$

c: $X=\mathrm{OMe}, \mathrm{Y}=\mathrm{N}(\mathrm{Me})_{2}, Z=\mathrm{MeO}$

d: $X=\mathrm{OMe}, Y=\mathrm{N}, Z=\mathrm{Me}$

e: $X=\mathrm{OMe}, Y=\mathrm{O}^{-}, Z=\mathrm{Me}$

f: $X=\mathrm{OMe}, Y=\mathrm{NMe}_{2}, Z=\mathrm{Me}$

g: $X, Y=O M e, Z=M e$

The lowest energy ground state structures of model anomeric amides 13a-e are shown in Fig. 2 and with the exception of $\mathbf{1 3 d}$ and $\mathbf{1 3 e}$, the nitrogens are pyramidal at nitrogen with average angles at nitrogen of well below $120^{\circ}$ and Winkler-Dunitz pyramidality indices, $\chi,^{52,53}$ in line with the total electronegativity of the two atoms attached to the amide nitrogen. $N$-Acetoxy- $N$-methoxyacetamide $\left(\chi=58^{\circ}\right)$ is very near to being fully $\mathrm{sp}^{3}$ hybridised at nitrogen $\left(\chi=60^{\circ}\right)$. The nitrogen in $N$ methoxy- $N$-methylthiylacetamide $\mathbf{1 3 b}\left(\chi=31.7^{\circ}\right)$ is a shallow pyramid while $N$-methoxy- $N$ dimethylaminoacetamide $\left(\chi=46.3^{\circ}\right)$ is moderately pyramidalised at the amide nitrogen. In the cases of 13a-c the Winkler-Dunitz twist parameters, $\tau,{ }^{52,53}$ are small, indicating good alignment of the lone pair orbital on nitrogen with the adjacent carbon $2 \mathrm{p}_{\mathrm{z}}$ orbital and some residual resonance in each case. However, $N-C(O)$ bonds are longer relative to $N, N$-dimethylacetamide $(1.378 \AA)$ and, based solely on $N-C(O)$ bond lengths, 13a would be expected to have the least residual resonance while that in $\mathbf{1 3 b}$ and $\mathbf{1 3 c}$ would be expected to be similar and less than that in 13a. The 1,1-diazene 13d is completely planar as is the hydroxamate 13e and both of these acetamides mirror the calculated structures of the formamide systems. ${ }^{5,41,45}$ The 1,1-diazene 13d would be expected to exhibit little resonance on account of the $N-N$ conjugation and ammonium character of the amide nitrogen and in keeping with this, has the longest $N-C(O)$ bond length of all five structures. $N-$ $C(O)$ is particularly long since both the $\mathrm{N} 1$ and $\mathrm{C} 2$ are also $\mathrm{sp}^{2}$ hybridised. While the computed 
structure of the hydroxamate anion 13e has a much shorter $N-C(O)$ bond, direct comparison with the B3LYP/6-31G(d) structures is not possible since at this level it is unstable and all data for 13e could only be computed at the HF/6-31G(d) at which it was at an electronic energy minimum. However, the electron-rich anion would be expected to exhibit significantly more resonance relative to $N, N$-dimethoxyacetamide or $N$-acetoxy- $N$-methoxyacetamide.

In 13a-c there is evidence of ground state anomeric effects. In 13a the C4-O3-N1-O2 dihedral aligns the $2 \mathrm{p}$ lone pair on $\mathrm{O} 3$ in the same plane as the N1-O2 $\sigma^{*}$ orbital. In $\mathbf{1 3 b}$ the dihedral angles predict that the p-type lone pairs located on S1 and $\mathrm{O} 2$ are similarly aligned with the N1-O2 and $\mathrm{N} 1-\mathrm{S} 1 \sigma^{*}$ orbitals respectively, while from dihedral angles in 13c, the lone pair on N2 deviates only ca 10 degrees from the plane of the N1-O3 $\sigma^{*}$ orbital.

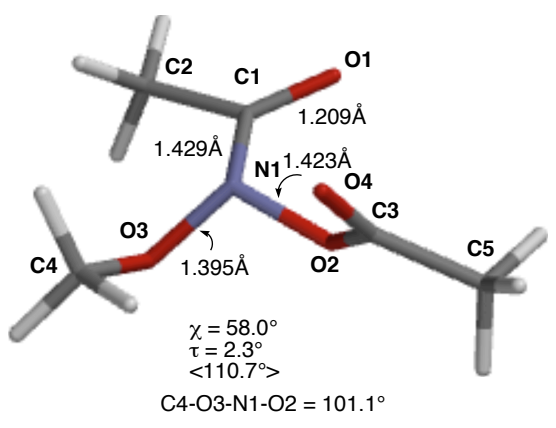

(a)

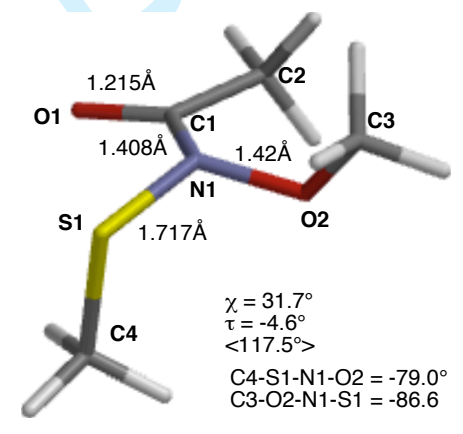

(b)

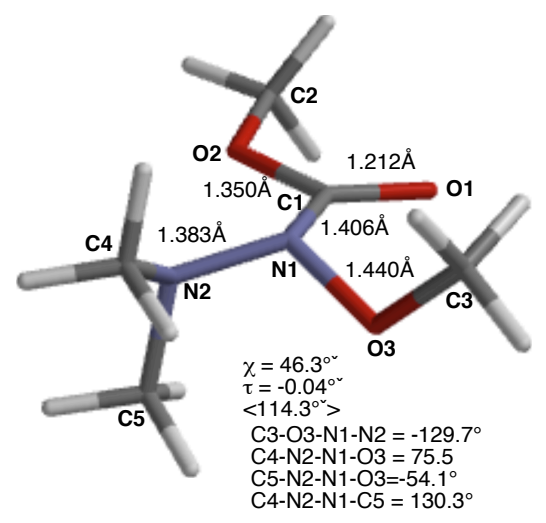

(c)

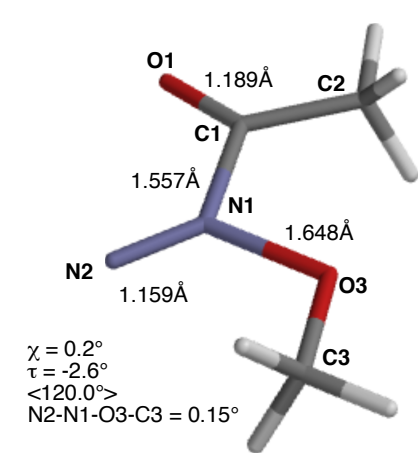

(d)

$1.564 \AA$

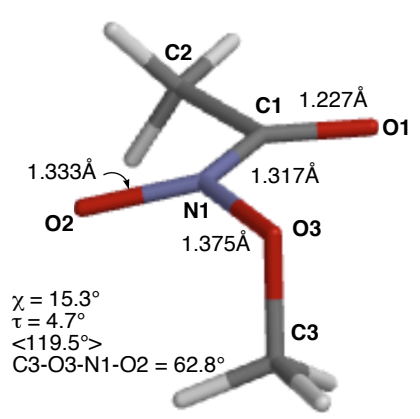

(e) 
Fig. 2 Lowest energy ground state structures for 13a-d (at B3LYP/6-31G(d)) and 13e (at HF/6$31 \mathrm{G}(\mathrm{d})) ; \chi$ and $\tau$ are the Winkler-Dunitz pyramidality and twist indices; ${ }^{53,53}$ average angles at nitrogen are denoted by $<>$.

Resonance effects in various anomeric amides 13a-c including 1,1-diazene 13d (formally an aminonitrene) and hydroxamate anions $\mathbf{1 3 e}$ have been computed using both our trans amidation method (eq. [1] $)^{47}$ and, for confirmation, Greenberg's COSNAR method (eq. [2]). ${ }^{48-50}$ B3LYP/6$31 G(d)$ performed well for the neutral systems 13a-d. In the trans amidation method we calculate destabilisation relative to $N, N$-dimethylacetamide 14 when anomeric amide $\mathbf{1 3}$ (with 16) is generated by transfer of the carbonyl to amine $\mathbf{1 5 .}$

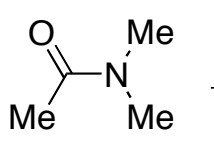

14

[1]

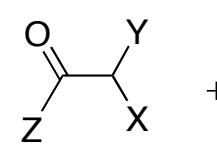

17

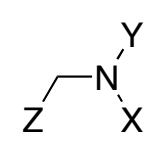

15

$$
\Delta E_{\text {react }}
$$

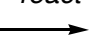

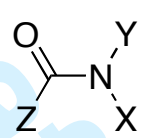

13

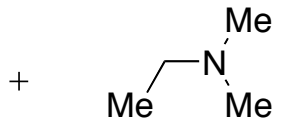

16

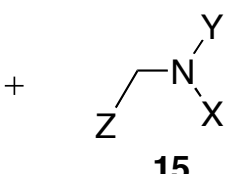

15
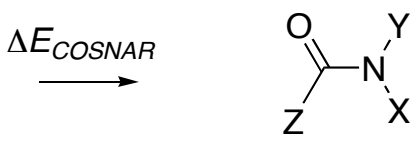

13

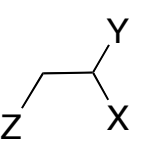

18
[2]

For the trans amidation method, the destabilisation relative to $N, N$-dimethylacetamide, $\Delta E_{\text {react }}$, also includes an inductive effect owing to the replacement of methyl groups at nitrogen in $\mathbf{1 4}$ by $X$ and $Y$ in 13. For 13a-c, this can be estimated isodesmically from formation of tricyclic systems 19-21, in which the resonance is zero, according to eq. [3] for 13a, eq. [4] for 13b and eq. [5] for 13c. Reduction of the overall destabilisation from eq. [1] by the inductive quantum gives the loss of 
energy relative to $N, N$-dimethylacetamide due to reduction in resonance alone. In the case of $\mathbf{1 3 d}$ and 13e, which have no tricyclic analogue, the inductive destabilisation can be estimated from eq. [6] in which the fully twisted forms 22 have little or no resonance. The twisted forms were obtained as rotational transition states. We have previously determined the maximum possible resonance loss, $\Delta E_{\max }$ for a simple amide to be $18.16 \mathrm{kcal} \mathrm{mol}^{-1}$ from the isodesmic reaction of $N, N$ dimethylacetamide with 1-azaadamantane to give 1-aza-2-adamantanone and $N, N$ dimethylethylamine, ${ }^{47}$ so the residual resonance stabilisation is given by eq. [7] in each case.

Computed RE's, together with the $\Delta E_{\text {react }}$ and $\Delta E_{\text {inductive }}$ destabilisation are presented in Table 1. These values were in close agreement with the values from COSNAR, which directly measures the increase in stabilisation when substituted nitrogen in $\mathbf{1 5}$ and carbonyl in $\mathbf{1 7}$ are adjacent in $\mathbf{1 3}$ with the expulsion of $\mathbf{1 8}$.<smiles>O=C1CC2CCN1CC2</smiles><smiles>O=C1ON2CCC1O2</smiles>

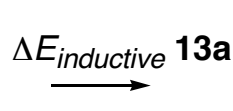<smiles>C1CN2CCC1CC2</smiles><smiles>O=C1CC2CC(=O)N1OO2</smiles>

19
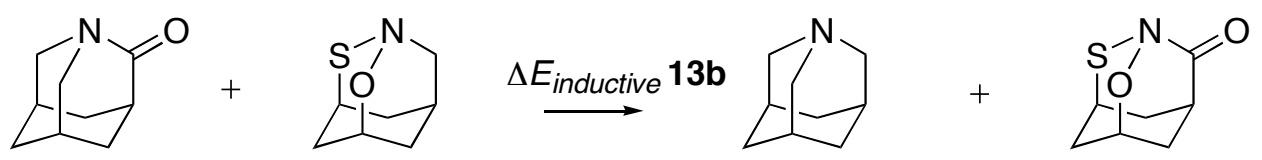

20

[4]

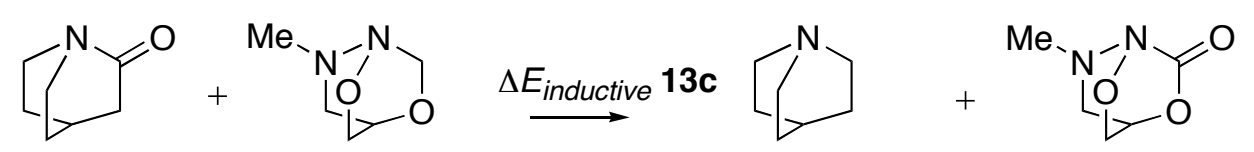

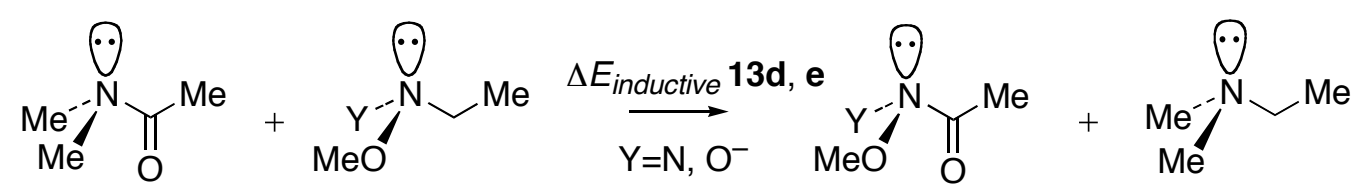


$\mathrm{RE}=-\left[\Delta E_{\text {max }}-\left(\Delta E_{\text {react }}-\Delta E_{\text {inductive }}\right)\right]=-\left[18.16-\left(\Delta E_{\text {react }}-\Delta E_{\text {inductive }}\right)\right]$

Resonance in the $N$-acetoxy- $N$-methoxyacetamide $\mathbf{1 3 a}(52-53 \%)$ relative to $N, N$-dimethylacetamide is similar to that previously obtained by similar methods for $N, N$-dimethoxyacetamide $\mathbf{1 3 g}(47 \%)^{9}$ and reflects comparable total electronegativity at the amide nitrogen. The reduced resonance also accords well with the x-ray structural properties of two $N$-acyloxy- $N$-alkoxyamides, which have $N-C(O)$ bonds of $1.44 \AA$ and similar pyramidality $\left(\chi=65^{\circ}\right.$ and $\left.66^{\circ}\right)$ and twist $\left(\tau=14^{\circ}\right.$ and $\left.15^{\circ}\right)$ to the model 13c. ${ }^{6,7}$

The $N$-methoxy- $N$-methylthiylacetamide system $\mathbf{1 3 b}$ represents intermediates $1 \mathbf{e}$ implicated in the reactions of $\mathrm{N}$-acyloxy- $\mathrm{N}$-alkoxyamides with thiols in Scheme 6. The reduced electronegativity of the sulfur atom results in a substantial increase in resonance delocalisation to about $71 \%$ that of $N, N$-dimethylacetamide.

Estimation of the extent of amide resonance for the carbamate 13c was best determined by trans carbamation to the substituted amine according to eq. [8]. However, the maximum loss of resonance for the carbamate, $\Delta E_{\max }$, is reduced relative to $N, N$-dimethylacetamide on account of competing resonance with the acyl oxygen, but can be estimated in an analogous fashion to that for $N, N$ dimethylacetamide $^{47}$ from the increase in energy upon formation of fully twisted 3-oxa-2quinuclidone from $\mathrm{N}, \mathrm{N}, \mathrm{O}$-trimethylcarbamate and 3-oxaquinuclidine, according to isodesmic eq. [9].<smiles>COC(=O)N(C)CON(C)C</smiles><smiles>COCN(C)C</smiles> 
${ }_{\mathrm{MeO}}^{\mathrm{O}} \mathrm{N}_{\mathrm{CH}_{3}}^{\mathrm{CH}_{3}}+\left[\mathrm{COO}_{\mathrm{O}}^{\mathrm{N}} \stackrel{\Delta E_{\max }=16.19 \mathrm{kcal} \mathrm{mol}^{-1}}{\longrightarrow}{ }_{\mathrm{MeO}}^{\mathrm{N}} \mathrm{CH}^{\mathrm{CH}_{3}}\right.$

Application of COSNAR (eq. [2]) to resonance in $\mathbf{1 3 c}$ results in a very different cross-conjugated configuration with attendant configurational stabilisation, which cannot be separated from resonance effects. For comparison with the trans carbamation result, resonance was best determined from the difference between two isodesmic COSNAR equations generating, respectively, an unconjugated, twisted carbamate (eq. [10]) and a conjugated carbamate (eq. [11]). The residual resonance percentages are in reasonable agreement $(63 \%$ and $67 \%$ of that in $N, N$ dimethylacetamide) and compare well with that obtained for $N$-methoxy- $N$ dimethylaminoacetamide ( $65 \%$ that of $N, N$-dimethylacetamide) ${ }^{46}$ Interestingly, from these results, the acyl oxygen appears to provide little competitive resonance in the carbamate.

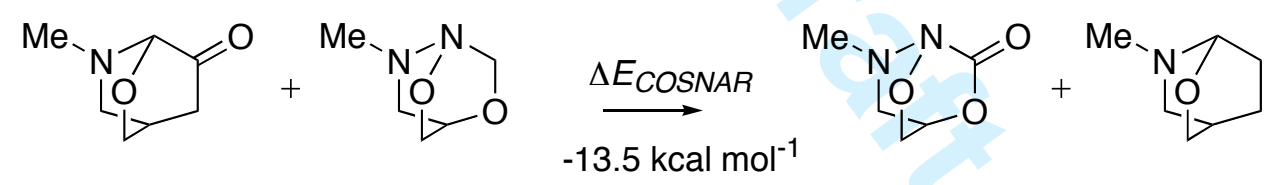

[10]

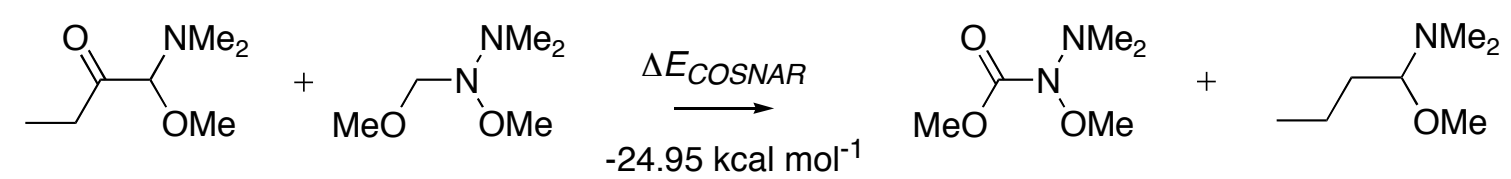

It was not possible to calculate the residual resonance in $N$-acetyl- $N$-methoxydiazene $\mathbf{1 3 d}$ by COSNAR method on account of spontaneous nitrene insertion reaction in the 1-methoxypropyl nitrene product required for eq. [2]. However, the trans amidation eq. [1] was successfully applied and confirms very low resonance of just $15 \%$ that of $N, N$-dimethylacetamide. 
The residual resonance in the hydroxamate 13e could only be computed at the HF/6-31G(d) level as at the B3LYP/6-31G(d) level with inclusion of electron correlation, and even upon incorporation of expanded basis sets and with the dispersion-corrected M06/6-311++G(d,p) method, the parent $N$ methoxyacetohydroxamate and amine anions relevant to both the COSNAR and the trans amidation reaction are unstable, generating instead partially dissociated complexes with methoxide. However, as an approximation, $\mathrm{HF} / 6-31 \mathrm{G}(\mathrm{d})$ energies afforded similar RE's of $6 \mathrm{kcal} \mathrm{mol}^{-1}$ and $8 \mathrm{kcal} \mathrm{mol}^{-1}$ or $36 \%-46 \%$ that of $N, N$-dimethylacetamide at the $\mathrm{HF} / 6-31 \mathrm{G}(\mathrm{d})$ level. 
Table 1. B3LYP/6-31G(d) derived COSNAR and trans amidation data for anomeric amides13a-e from eq.'s [1-11] together with that for $\mathbf{1 3 f}$ and $\mathbf{1 3 g}$

\begin{tabular}{ll}
\hline Structure & Energy $\left(\mathrm{kcal} \mathrm{mol}^{-1}\right)^{a, b}$ \\
\hline$N$-Acetoxy- $N$-methoxyacetamide 13a & $-9.5[52 \%]$ \\
$\Delta E_{C O S N A R}$ from eq. [2] & 15.6 \\
$\Delta E_{\text {react }}$ from eq. [1] & 7.1 \\
$\Delta E_{\text {inductive }}$ eq. [3] & $-9.7[53 \%]$ \\
RE eq. [7] & \\
\hline$N$-Methoxy- $N$-methylthiylacetamide 13b & $-13.0[71 \%]$ \\
$\Delta E_{C O S N A R}$ from eq. [2] & 6.4 \\
$\Delta E_{\text {react }}$ from eq. [1] & 1.2 \\
$\Delta E_{\text {inductive }}$ eq. [4] & $-13.0[71 \%]$ \\
RE from eq. [7]
\end{tabular}

$\mathrm{N}$-Methoxy- $N$-dimethylamino-O-methylcarbamate 13c

$\Delta E_{\text {COSNAR }}$ from (eq. [11-10])

$-11.4[63 \%]$

$\Delta E_{\text {react }}$ from eq. [8]

7.6

$\Delta E_{\text {inductive }}$ from eq. [5]

3.5

RE from [-16.19-(eq. [8-5])]

$-12.1[67 \%]$

1-Acetyl-1-methoxydiazene 13d

$\Delta E_{\text {COSNAR }}$

$-\mathrm{C}$

$\Delta E_{\text {react }}$ from eq. [1]

24.1

$\Delta E_{\text {inductive }}$ from eq. [6], $\mathrm{Y}=\mathrm{N}$

9.5

RE from eq. [7]

$-3.5[14.8 \%]$

$N$-Methoxyacetohydroxamate anion $\mathbf{1 3} \mathbf{e}^{d}$

$\Delta E_{\text {COSNAR }}$ from eq. [2] $-6.2[36 \%]$ 
$\Delta E_{\text {react }}$ from eq. [1] $\quad 5.4$

$\Delta E_{\text {inductive }}$ eq. [6], $\mathrm{Y}=\mathrm{O}^{-} \quad 1.0$

RE from eq. [7] - -7.8 [46\%]

$\begin{array}{ll}N \text {-Methoxy- } N \text {-dimethylaminoacetamide } \mathbf{1 3 f}{ }^{e} & \\ \Delta E_{\text {COSNAR }} & -12.5[69 \%] \\ \Delta E_{\text {react }} & 8.4 \\ \Delta E_{\text {inductive }} & 2.4 \\ \operatorname{RE} & -12.2[67 \%] \\ N, N \text {-Dimethoxyacetamide } \mathbf{1 3 g}{ }^{f} & \\ \Delta E_{\text {CosNAR }} & -8.6[47 \%] \\ \Delta E_{\text {react }} & 13.9 \\ \Delta E_{\text {inductive }} & 4.3 \\ \mathrm{RE} & -8.6[47 \%]\end{array}$

${ }^{a}$ Relative to the energy of $N, N$-dimethylacetamide

${ }^{b}$ Amidicities in parentheses.

${ }^{c}$ Not applicable

${ }^{d}$ Computed at the HF/6-31G(d) level.

${ }^{e}$ Previously published values ${ }^{46}$

${ }^{f}$ Previously published values ${ }^{9}$ 
Transition states for the HERON reactions of 13a-e are shown in Fig. 3 and relevant ground state conformer energies, activation energies $\left(E_{\mathrm{A}}\right)$ and reaction energies $(\Delta E)$ are collated in Table 2 . In all cases, the transition sates possessed one imaginary frequency and relaxed to reactant and product from coordinates either side of them.

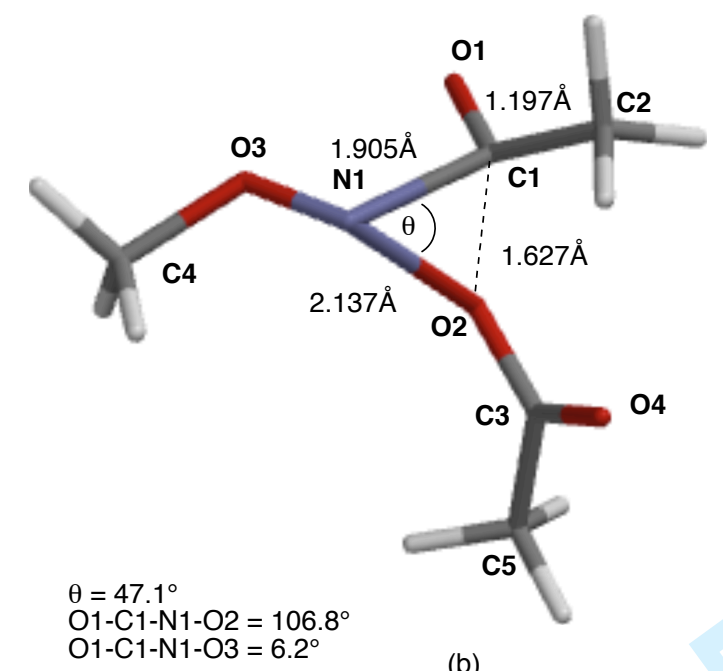

$\mathrm{O} 1-\mathrm{C} 1-\mathrm{N} 1-\mathrm{O} 2=106.8^{\circ}$

(b)

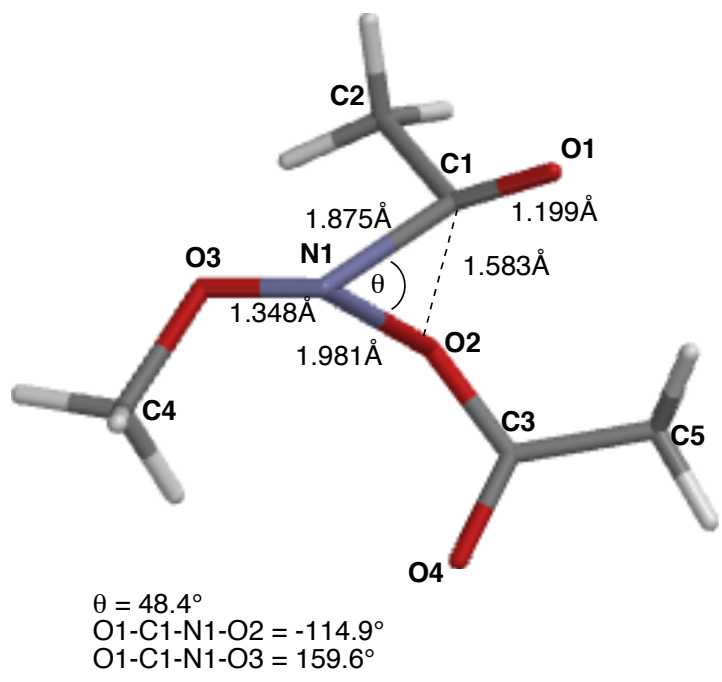

(a)

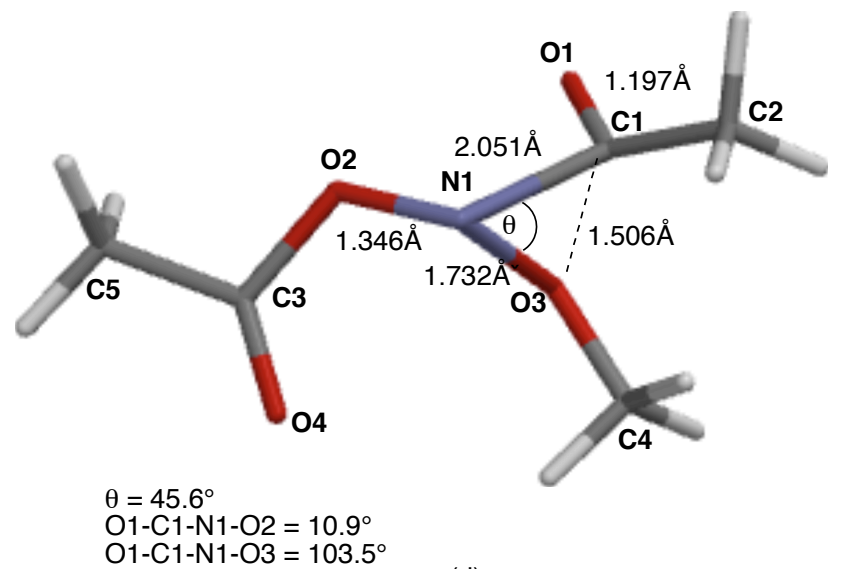

(d)

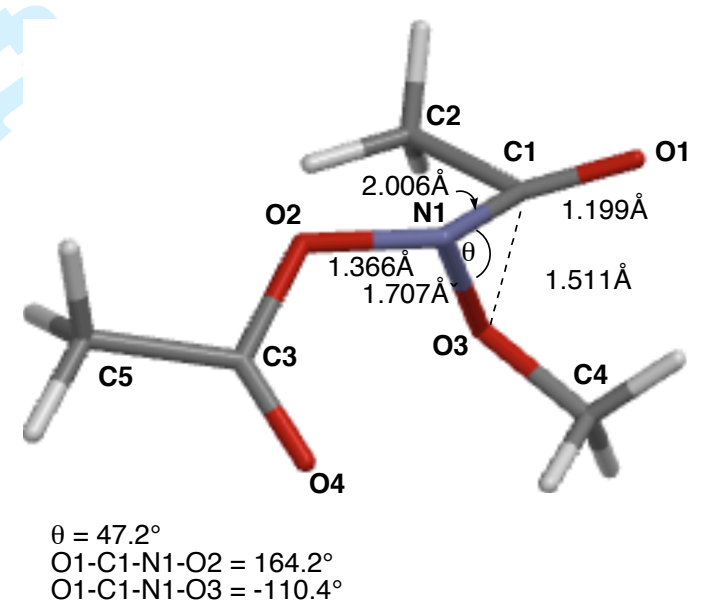

(c)

Fig. 3. B3LYP/6-31G(d) optimised transition states for migration of acetoxyl from (a) syn and (b) anti conformers of $N$-acetoxy- $N$-methoxyacetamide 13a and migration of methoxyl from (c) anti and (d) syn conformers of $N$-acetoxy- $N$-methoxyacetamide 13a. 


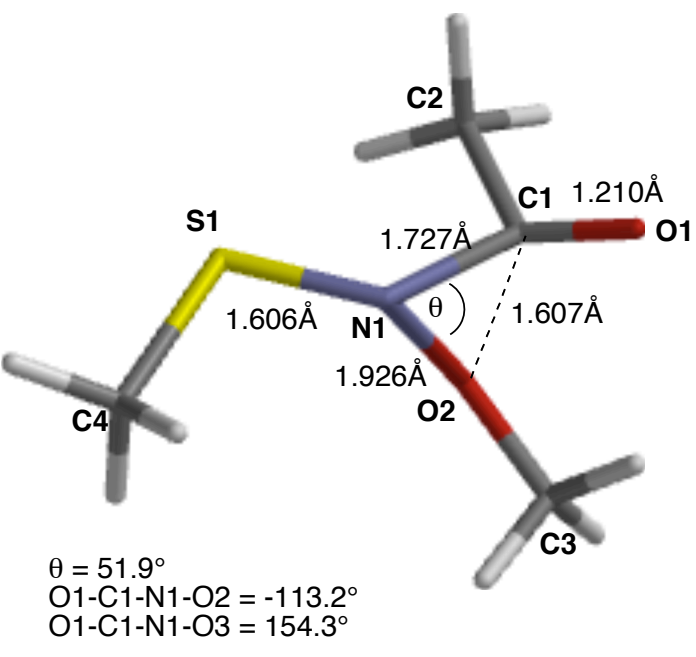

(b)

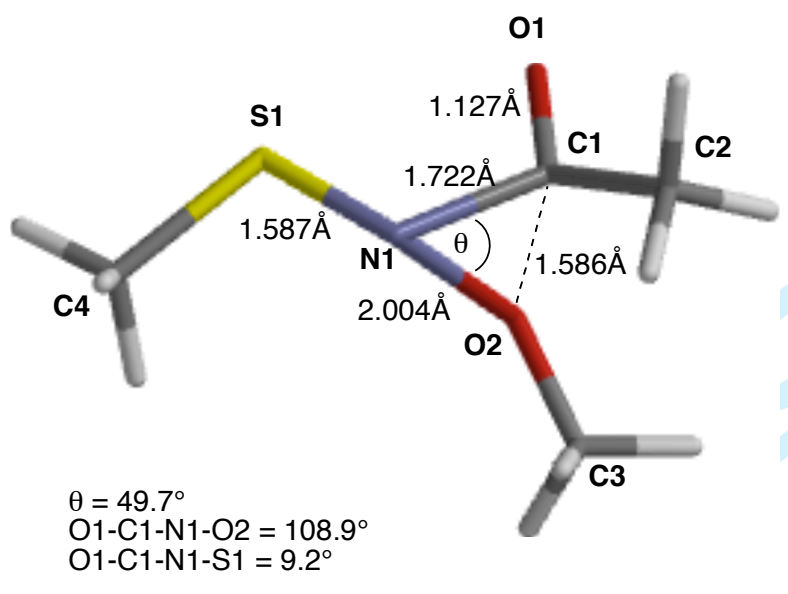

(a)

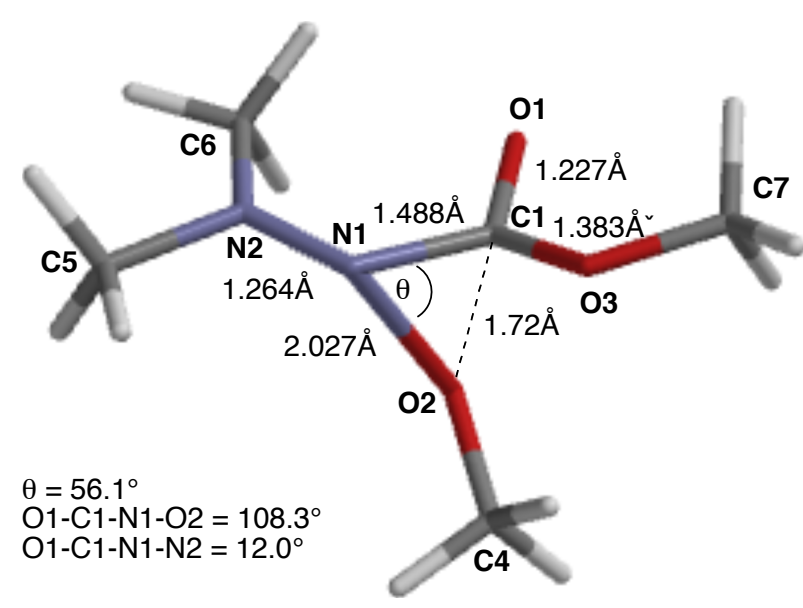

(d)

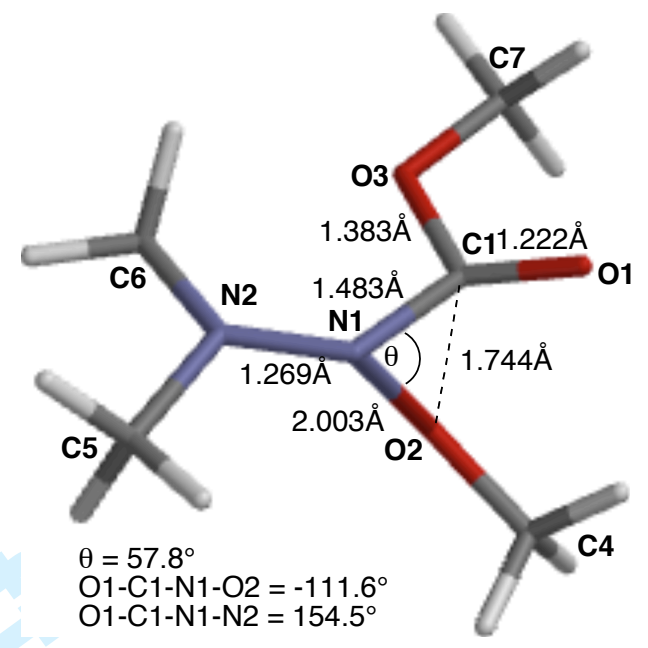

(c)

Fig. 4. B3LYP/6-31G(d) optimised transition states for migration of methoxyl from (a) syn and (b) anti conformers of $N$-methoxy- $N$-methylthiylacetamide $\mathbf{1 3 b}$ and migration of methoxyl from (c) syn and (d) anti conformers of $N$-methoxy- $N$-dimethylamino- $O$-methylcarbonate $13 \mathbf{c}$. 


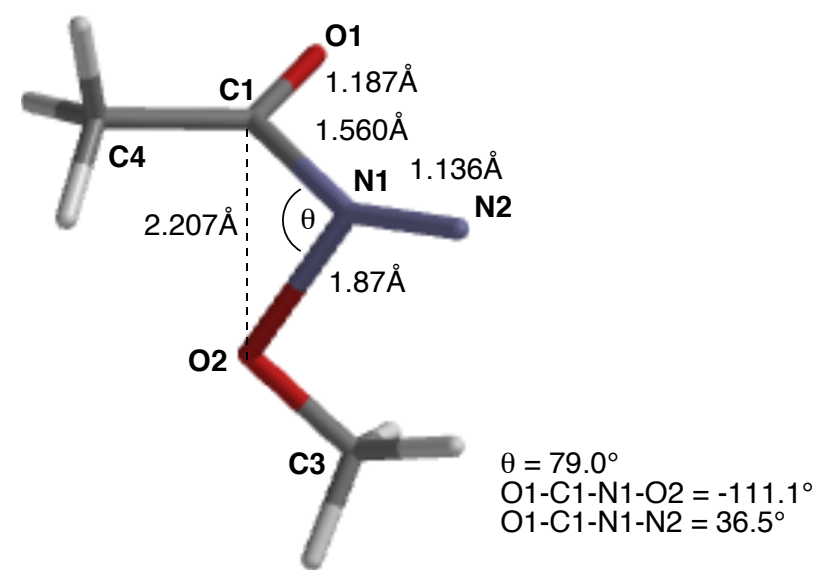

(a)

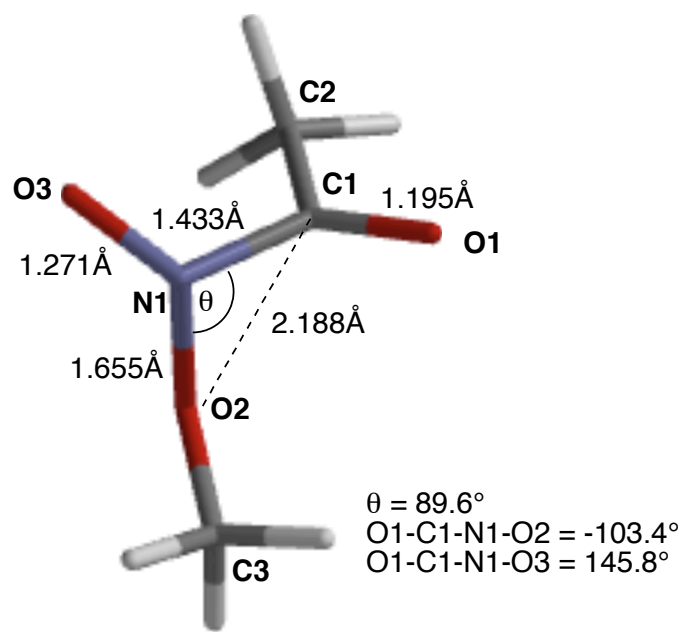

(b)

Fig. 5. (a) B3LYP/6-31G(d) optimised transition state for migration of methoxyl in 1-acetyl-1methoxydiazene 13d and (b) HF/6-31G(d) optimised transition state for migration of methoxyl in $N$-methoxyacetohydroxamate $\mathbf{1 3 e}$. 
Table 2. B3LYP/6-31G(d) derived relative energies of conformers, transition states and products for HERON reactions of 13a-e and $19 .^{a}$

\begin{tabular}{|c|c|}
\hline Structure & $E_{r e l}\left(\mathrm{kcal} \mathrm{mol}^{-1}\right)^{b}$ \\
\hline \multicolumn{2}{|l|}{$N$-Acetoxy- $N$-methoxyacetamide $13 a$} \\
\hline Syn & 0 \\
\hline Anti & $0.57(0.6)$ \\
\hline$E_{\mathrm{A}}$ AcO migration from $\operatorname{syn}(i 308)$ & $43.3(41.2)$ \\
\hline$E_{\mathrm{A}}$ AcO migration from anti (i 314) & $43.4(41.6)$ \\
\hline$E_{\mathrm{A}} \mathrm{MeO}$ migration from syn $(i 255)$ & $49.6(48.1)$ \\
\hline$E_{\mathrm{A}} \mathrm{MeO}$ migration from anti $(i 243)$ & $43.7(42.4)$ \\
\hline$\Delta E_{C}$ Acetic anhydride + methoxynitrene $(\mathrm{S})$ complex & 30.4 \\
\hline$\Delta E_{S}$ Acetic anhydride + methoxynitrene $(\mathrm{S})$ & $36.8(34.3)$ \\
\hline$\Delta E_{T}$ Acetic anhydride + methoxynitrene $(\mathrm{T})$ & $19.1(21.7)$ \\
\hline$\Delta E_{C}$ Methyl acetate + acetoxynitrene $(\mathrm{S})$ complex & 37.2 \\
\hline$\Delta E_{S}$ Methyl acetate + acetoxynitrene $(\mathrm{S})$ & $35.2(33.0)$ \\
\hline$\Delta E_{T}$ Methyl acetate + acetoxynitrene $(\mathrm{T})$ & $14.9(13.2)$ \\
\hline
\end{tabular}

\section{$N$-Methoxy- $N$-methylthiylacetamide 13b}

Syn

Anti

$E_{\mathrm{A}} \mathrm{MeO}$ migration from anti $(i 398)$

$41.6(39.8)$

$E_{\mathrm{A}} \mathrm{MeO}$ migration from syn (i 368)

$\Delta E_{C}$ Methylacetate + methylthionitrene $(\mathrm{S})$ complex

12.4

$\Delta E_{S}$ Methylacetate + methylthionitrene (S)

$\Delta E_{T}$ Methylacetate + methylthionitrene $(\mathrm{T})$

$\Delta E_{S} S$-methyl ethanethioate + methoxynitrene (S)

$58.8(56.0)$ 
$N$-Methoxy- $N$-dimethylamino- $O$-methylcarbamate $13 \mathrm{c}$

Syn

0

Anti

$0.25(0)$

$E_{\mathrm{A}} \mathrm{MeO}$ migration from anti (i 240)

$22.1(20.5)$

$E_{\mathrm{A}} \mathrm{MeO}$ migration from syn (i 250)

$24.4(22.9)$

$\Delta E_{C}$ Dimethyl carbonate +1 ,1-dimethyldiazene complex

$-5.5$

$\Delta E_{S}$ Dimethyl carbonate $+1,1-$ dimethyldiazene (S)

$0.16(-1.6)$

\section{1-Acetyl-1-methoxydiazene 13d}

Anti

0

Syn

$E_{\mathrm{A}}$ Transition state $(i$ 187)

$\Delta E_{C}$ Methylacetate + nitrogen complex

$\Delta E_{S}$ Methylacetate + nitrogen

$-93.6(-93.1)$

\section{$N$-Methoxyacetohydroxamate anion $13 \mathrm{e}^{c}$}

Anti

0

Syn

$6.6(6.4)$

$E_{\mathrm{A}}$ Methoxy migration from anti $(i 301)$

$11.5(10.0)$

$\Delta E$ Tetrahedral intermediate

$\Delta E_{S}$ Methyl acetate + nitroxide anion $(\mathrm{S})$

$\Delta E_{T}$ Methyl acetate + nitroxide anion $(\mathrm{T})$

$-33.0(-33.8)$ 
$E_{\mathrm{A}}$ Acyloxyl migration (i 330)

$31.9(30.6)$

$E_{\mathrm{A}}$ Alkoxyl migration (i 342)

$38.6(37.2)$

$\Delta E_{C}$ Anhydride complex 27

11.1

$\Delta E_{C}$ Lactone complex 28

25.5

\footnotetext{
${ }^{a}$ Absolute energies are given in the supplementary information.

${ }^{b}$ Energies of conformers, transition states $\left(E_{\mathrm{A}}\right)$ and relaxed transition state complexes $\left(\Delta E_{C}\right)$ and products $\left(\Delta E, \Delta E_{\mathrm{S}}\right.$ and $\left.\Delta E_{\mathrm{T}}\right)$ relative to the respective lowest energy ground state; enthalpy corrected values in parentheses.

${ }^{c}$ Computed at HF/6-31G(d) level
} 
Since conformers of $N$-acetoxy- $N$-methoxyacetamide 13a are very close in energy and both nitrogen substituents are bonded through oxygen, rearrangement of both acetoxyl and methoxyl were computed leading to four transition states. While acetoxyl migration from the lowest energy, syn rotamer is more favourable by $c a 6 \mathrm{kcal} \mathrm{mol}^{-1}$ relative to methoxyl migration, methoxyl and acetoxyl migrations from the anti form have similar $E_{\mathrm{A}}$ 's. Experimentally, in the limited cases studied to date, the major reaction pathways result from acyloxyl migration to give anhydrides and alkoxynitrenes together with radical homolysis. ${ }^{43}$ While esters are generated in those reactions, they can be formed indirectly by either of those processes. However, their formation by HERON migration of alkoxyl groups cannot be discounted since the properties of acyloxynitrenes, which would be formed in concert with HERON migration to form esters are unknown, as are their reactivities. The significantly higher $E_{\mathrm{A}}$ calculated for rearrangements of 13a is in line with the experimental decompositions of $N$-acyloxy- $N$-alkoxyamides in non-polar solvents, which occur at temperatures above $90^{\circ} \mathrm{C}$. The transition states are all similar and indicate breaking of the $N-C(O)$ bond in concert with $\mathrm{O}-\mathrm{C}$ bond formation. In step with this, double bond character in the amide carbonyls is conserved at the transition state and their lengths are virtually unchanged from that in the ground state structure Fig. 1a (1.209 ̊). Both reactions, with conservation of singlet character are endothermic but relaxation of the transition states affords a complex between acetic anhydride and methoxynitrene from transition state Fig. 3a (Fig. 6a) and one between methylacetate and acetoxynitrene from Fig. 3d (Fig. 6b). The very long acyl $C-O N$ bond (1.825 $\AA$ ) in this complex suggests partial dissociation and instability of acetoxynitrene although similar lengthening to $1.99 \AA$ is also found in the isolated gas phase structure, which is at a minimum on the potential surface of the acetoxynitrene. The complexes are endothermic by respectively $30.4 \mathrm{kcal} \mathrm{mol}^{-1}$ and $37.2 \mathrm{kcal}$ $\mathrm{mol}^{-1}$ and respectively $6.4 \mathrm{kcal} \mathrm{mol}^{-1}$ more stable and $2.0 \mathrm{kcal} \mathrm{mol}^{-1}$ less stable than the separated gas phase products. 


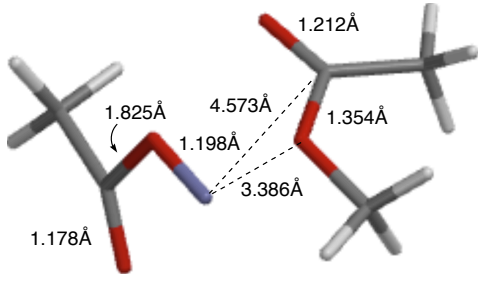

(b)

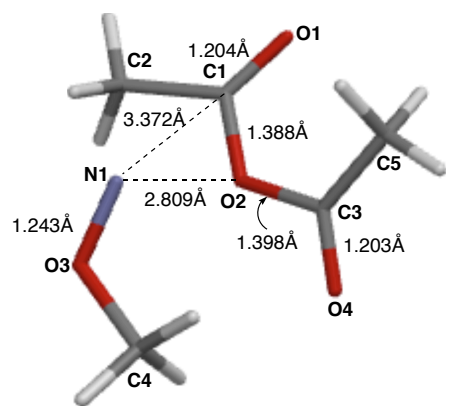

(a)

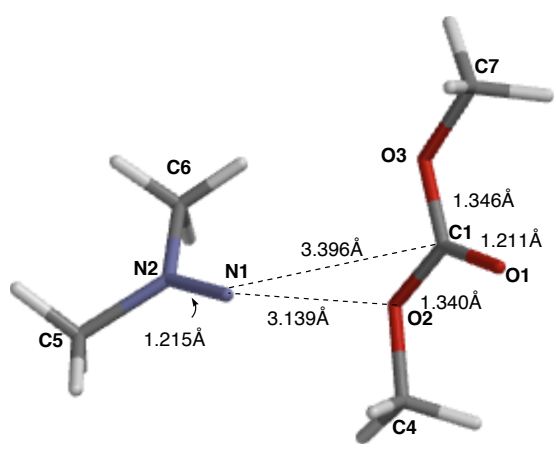

(d)

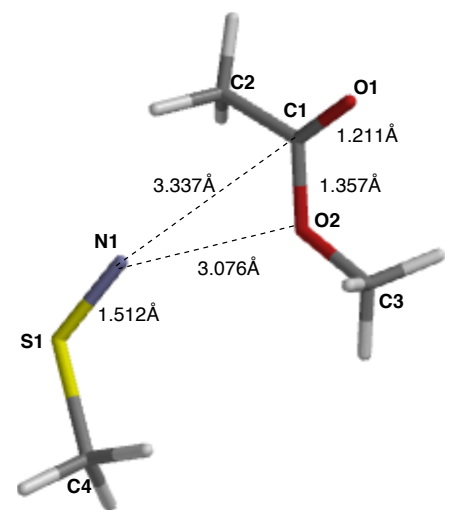

(c)

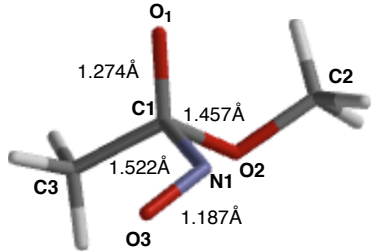

(f)

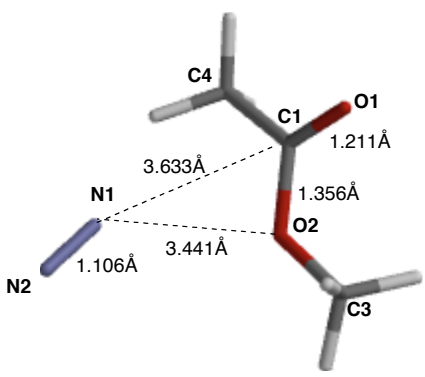

(e)

Fig. 6. Products and product complexes from relaxation of lowest energy transition states for HERON reactions of 13a-e transition states.

Though $N$-alkoxy- $N$-alkylthiylamides 1 e are implicated as intermediates in the reactions of $N$ acyloxy- $N$-alkoxyamides 1a with thiols (Scheme 6), no HERON reactivity was detected and this pathway is clearly not competitive with bimolecular substitution at sulfur. Nonetheless, sulfur and oxygen substitution at nitrogen is an unusual arrangement that could lead to either esters or S-alkyl alkylthioates and the corresponding nitrenes by HERON reactions (Scheme 7) and the energetics and possibilities for HERON rearrangement are interesting by way of comparison with other, similar anomeric amides.

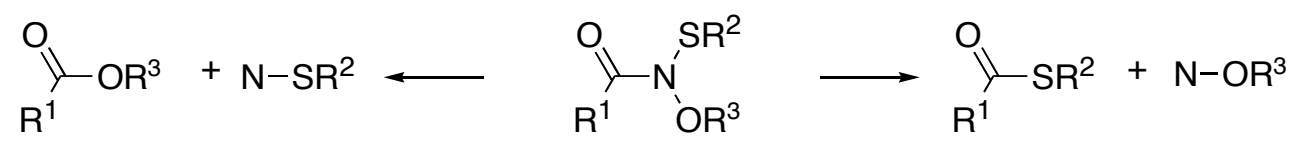

Scheme 7 
The HERON reactions of model $N$-methoxy- $N$-methylthiylacetamide $\mathbf{1 3 b}$ can, in theory, involve migration of methoxyl or the methylthiyl substituent. However, transition states can only be found for translocation of methoxyl to give methyl acetate and methylthionitrene (Fig. $4 \mathrm{a}$ and b). Migration of methoxyl from the anti form with carbonyl oxygen and sulfur anti in the transition state has the lowest $E_{\mathrm{A}}$, though the anti form is slightly less stable. Activation energies $\left(E_{\mathrm{A}}\right)$ of both migrations are of the same order as those for migration of acetoxyl in $N$-acetoxy- $N$ methoxyacetamide 13a (Table 3). Methoxyl migration is again in concert with heterolysis of the $N-C(O)$ bond as evidenced by the much longer $N-C(O)(1.72 \AA)$ relative to the ground state $(1.41$ $\AA$ ). Developing thiylnitrene character is also evident in the shortening of the $S-N$ bond from 1.717 $\AA$ to $1.59-1.6 \AA$ ). Relaxation of the methoxyl migration transition states affords either $\mathbf{1 3 b}$ or, in the forward direction, a complex (Fig. 6c) between methyl acetate and singlet methylthionitrene which is $7.3 \mathrm{kcal} \mathrm{mol}^{-1}$ more stable than its constituents in the gas phase. No transition state could be found for sulfur migration in either rotamer of $\mathbf{1 3 b}$ and the reaction is predicted to be highly endothermic. S-Methyl ethanethioate and methoxynitrene would not appear to be a stationary point on the reaction profile.

Syn and anti forms of model $N$-methoxy- $N$-dimethylamino- $O$-methylcarbamate $13 \mathbf{c}$ are comparable in energy, and methoxyl migration from each occurs with similar $E_{\mathrm{A}}$ 's of $24.4 \mathrm{kcal} \mathrm{mol}^{-1}$ and 22.1 $\mathrm{kcal} \mathrm{mol}^{-1}$. These much lower activation barriers for the formation of dimethylcarbonate from $\mathrm{N}$ methoxy- $N$-dimethylamino- $O$-methylcarbamate are in accord with their reactions in solution according to Scheme 2, which occur at room temperature and in which dialkyl carbonates 6 and 1,4dimethyl-1,4-diaryltetrazene (from dimerisation of 1,1-diazene 7) are generated from reaction of $\mathrm{N}$ acyloxy- $N$-alkoxycarbamates 4 and $N$-methylarylamines. ${ }^{42}$ The transition state geometries (Fig. $4 \mathrm{c}$ and 4d) and energies (Table 2) are similar in most respects to those for migration of methoxy in $\mathrm{N}$ methoxy- $N$-dimethylaminoacetamide $\left(E_{\mathrm{A}}=22.7 \mathrm{kcal} \mathrm{mol}^{-1}\right) .^{40,46}$ At the lowest energy transition 
state, there is appreciable lengthening of the $N-C(O)$ bond (by $0.08 \AA$ ) and shortening of the $N-N$ bond (by $0.02 \AA$ ) relative to $\mathbf{1 3 c}$, indicating cleavage of the $N-C(O)$ bond with developing 1,1 diazene character. Like the HERON rearrangement of $\mathbf{1 3 f}$, which is computed to be slightly exothermic, the carbamate reaction is computed to be almost thermoneutral. The transition state in Fig. 4c generates 13c in the reverse direction and in the forward direction, well separated 1,1dimethyldiazene and dimethyl carbonate (Fig. 6d), which is lower in energy by $5.5 \mathrm{kcal} \mathrm{mol}^{-1}$ relative to the isolated nitrene and carbonate.

As has been determined computationally in several previous high-level studies on 1-formyl-1methoxydiazene, ${ }^{5,45}$ the 1-acetyl-1-methoxydiazene $\mathbf{1 3 d}$ rearranges similarly with a minimal $E_{\mathrm{A}}$ of $2.1 \mathrm{kcal} \mathrm{mol}^{-1}$. Only one transition state is formed from syn and anti forms and is very early along the reaction coordinate leading to nitrogen and methyl acetate in a highly exothermic process. Consequentially, there is a large $C N O$ angle $\left(79^{\circ}\right)$ and minimal lengthening of the $N-C(O)$ bond relative to ground state (Fig. 4a). The transition state resembles reactants but reverts to the diazene or proceeds to separated methyl acetate and nitrogen (Fig. 6e) at geometries before and after the saddle point.

The transition state for rearrangement of $\mathbf{1 3 e}$ could not be located at the B3LYP/6-31G(d) level. However, consistent with the successful calculation of resonance energy at the HF/6-31G(d) level of theory, the lowest energy form of the anion 13e rearranges in an exothermic reaction with an early transition state that resembles reactants and with an $E_{\mathrm{A}}$ of $11.5 \mathrm{kcal} \mathrm{mol}^{-1}$. As determined at the $\mathrm{HF} / 6-31 \mathrm{G}(\mathrm{d})$ level this reaction is not a true HERON process since, while rearrangement of methoxyl from nitrogen to carbon occurs, there is no cleavage of the $N-C$ bond in concert with that migration and a tetrahedral intermediate is generated, which would presumably lead to $\mathrm{NO}^{-}$and methyl acetate, according to the products observed experimentally when $N$-acyloxy- $N$ alkoxyamides $1 \mathrm{a}$ are treated with base (Scheme 5). ${ }^{17}$ Shortening the $\mathrm{N}-\mathrm{OMe}$ bond resulted in an 
intermediate rotamer of $\mathbf{1 3 e}$ with the lone pair syn to the carbonyl, which is a local minimum on the amide rotational energy profile. Relaxation in the forward direction produced the tertiary alkoxide (Fig. 6f), which is thermally more stable than reactant by $16 \mathrm{kcal} \mathrm{mol}^{-1}$. The elongated $\mathrm{C} 1-\mathrm{O} 1$ bond (1.274 $\AA$ ) and charge on the O1 (-0.989) are consistent with its formation.

The computed $E_{\mathrm{A}}$ 's for HERON reactions is composed of the RE, which is lost in the process as well as a rearrangement component, $E_{\text {rearr }}$. Without deconvolution of the total $E_{\mathrm{A}}$, the influence of various substituents on the ease of migration is unclear since substituents affect both the RE and the migration. However, reduction of the total $E_{\mathrm{A}}$ by the RE in each case provides more reliable insight into the relative influence of substituents as well as other important features of the HERON process. The nature of the migrating group, the role of acyl substituents and conformation in the ground states are also relevant factors that can affect HERON activation energies.

Activation energies $\left(E_{\mathrm{A}}\right)$, resonance energies (RE) and derived rearrangement energies $\left(E_{\text {rearr }}\right)$ for amides 13a-e are collated in Table 3, together with previous data for $N$-methoxy- $N$ dimethylaminoacetamide 13f, $N, N$-dimethoxyacetamide $\mathbf{1 3 g}$, two lactam forms of $\mathbf{1 3 g}, \mathbf{2 3}$ and 24 and resonance energies of $N$-chloro analogues $\mathbf{2 5}$ and $\mathbf{2 6 .}$

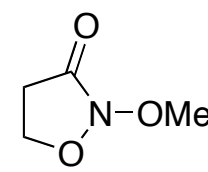

23

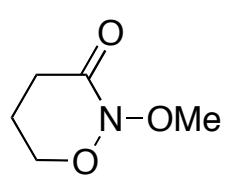

24<smiles>CON(Cl)C(C)=O</smiles>

25<smiles>[R]N(Cl)N(Cl)C(C)=O</smiles>

26

a: $\mathrm{R}=\mathrm{Me}$

b: $\mathrm{R}=\mathrm{H}$ 
Table 3. Activation energies $\left(E_{\mathrm{A}}\right)$, resonance energies $(\mathrm{RE})$ and rearrangement energies $\left(E_{\text {rearr }}\right)$ for HERON reactions of amides 13a-g, 19, 23-24 and resonance energies for $\mathbf{2 5}$ and $\mathbf{2 6}$.

\begin{tabular}{|c|c|c|c|c|}
\hline Migratory mode & $E_{\mathrm{A}}\left(\mathrm{kcalmol}^{-1}\right)$ & $\mathrm{RE}\left(\mathrm{kcal} \mathrm{mol}^{-1}\right)$ & & $E_{\text {rearr. }}\left(\mathrm{kcal} \mathrm{mol}^{-1}\right)^{\mathrm{a}}$ \\
\hline & & Trans amidation & COSNAR & \\
\hline $\mathrm{AcO}$ from syn $\mathbf{1 3 a}$ & 43.27 & -9.68 & -9.48 & $33.59(33.79)$ \\
\hline $\mathrm{MeO}$ from syn $\mathbf{1 3 a}$ & 49.68 & -9.68 & -9.48 & $40.00(40.20)$ \\
\hline $\mathrm{AcO}$ from anti $\mathbf{1 3 a}$ & 43.39 & -9.68 & -9.48 & $33.71(33.91)$ \\
\hline $\mathrm{MeO}$ from anti $\mathbf{1 3 a}$ & 43.68 & -9.68 & -9.48 & $34.00(34.20)$ \\
\hline $\mathrm{MeO}$ from anti $\mathbf{1 3 b}$ & 41.6 & -12.97 & -12.97 & 28.63(28.63) \\
\hline $\mathrm{MeO}$ from syn $\mathbf{1 3 b}$ & 44.27 & -12.97 & -12.97 & $31.30(31.30)$ \\
\hline $\mathrm{MeO}$ from anti $13 \mathrm{c}$ & 24.42 & -12.11 & -11.4 & $12.31(3.02)$ \\
\hline $\mathrm{MeO}$ from syn $13 \mathrm{c}$ & 22.09 & -12.11 & -11.4 & $9.98(10.69)$ \\
\hline $\mathrm{MeO}$ from 13d & 2.1 & -3.54 & - & $-1.44(-)$ \\
\hline $\mathrm{MeO}$ from $13 \mathbf{e}$ & 11.48 & -7.75 & -6.17 & $3.73(5.31)$ \\
\hline $\mathrm{MeO}$ from syn $\mathbf{1 3 f}^{b}$ & 22.7 & -12.3 & -12.5 & $10.40(10.20)$ \\
\hline $\mathrm{MeO}$ from $13 \mathbf{g}^{b}$ & 37.4 & -8.59 & -8.58 & $28.81(28.82)$ \\
\hline Acyloxyl from 19 & 31.9 & 0 & 0 & 31.9 \\
\hline Alkoxyl from 19 & 38.6 & 0 & 0 & 38.6 \\
\hline Ring opening $\mathbf{2 3}^{c}$ & 27 & -4.59 & -4.78 & $22.41(22.22)$ \\
\hline Ring contraction $\mathbf{2 4}^{c}$ & 34.7 & -8.78 & -8.97 & $25.92(25.73)$ \\
\hline Ring opening $\mathbf{2 4}^{c}$ & 32.6 & -8.78 & -8.97 & $23.82(23.63)$ \\
\hline $25^{d}$ & - & -7.04 & $-7.07(8.21)$ & - \\
\hline $\mathbf{2 6 \mathbf { a } ^ { d }}$ & - & -6.93 & $-6.86(11.62)$ & - \\
\hline $26 \mathbf{b}^{d}$ & - & -7.78 & $-7.78(10.98)$ & - \\
\hline
\end{tabular}

\footnotetext{
${ }^{a}$ Trans amidation data; COSNAR-derived values in parentheses

${ }^{b}$ Previously published values ${ }^{46}$
} 
${ }^{c}$ Previously published values ${ }^{11,46}$

${ }^{d}$ Previously published values; ${ }^{12}$ M06/6-311++G(d,p) COSNAR values in parentheses. 
Acetoxyl migrations from either rotamer of $N$-acetoxy- $N$-methoxyacetamide 13a have slightly higher $E_{\text {rearr }}$ 's to that previously computed for $N, N$-dimethoxyacetamide $\mathbf{1 3 g}$, for which homolysis with a lower $E_{\mathrm{A}}$ is the preferred mode of reaction upon thermolysis. While the difference between $E_{\text {rearr. }}$ for acetoxyl and methoxyl migrations is significant from the syn form, it is only marginally favoured starting from the anti form. The preference for acetoxyl migration in the thermal decomposition of $\mathrm{N}$-acyloxy- $\mathrm{N}$-alkoxyamides in non-polar solvent may also be dependent upon other factors, such as steric effects in the transition state or factors that control the syn-anti energies, such as steric and pi-pi stacking effects (where aromatic substituents are present); two solid-state structures for which we have $\mathrm{x}$-ray structural data are both syn conformers with evidence for pi-pi stacking between aromatic side chains. ${ }^{6}$ Inspection of the computed transition states in Fig. 3 indicates that alkoxyl migration from the syn form shown in Fig. 3d would invoke significant steric interaction between the alkoxyl group and the acyl substituent, which would be less important in acyloxyl migrations or in the migration of alkoxyl from the anti conformer.

Relative migratory aptitudes of alkoxyl and acyloxyl in the absence of any resonance can also be estimated from rearrangement of the fully twisted 2',2"-dioxa-2,3'-quinuclidione 19, which generates anhydride $\mathbf{2 7}$ or lactone $\mathbf{2 8}$ by migration of acyloxyl and alkoxyl branches, respectively (Scheme 8). B3LYP/6-31G(d) optimised ground state 19, transition states and relaxed products are depicted in Fig. 7 and energies are given in Table 2.

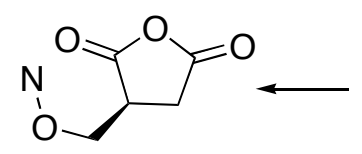

27

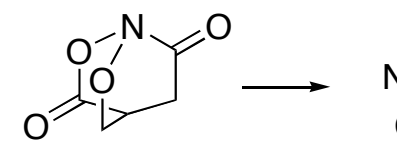

19<smiles>NOC(=O)C1COC(=O)C1</smiles>

28

Scheme 8 
Both transition states (Fig. $7 \mathrm{~b}$ and c) resemble those for the acetamide system and relax in the forward direction to intramolecular complexes of alkoxynitrene and anhydride (27, Fig. 7d) and acyloxynitrene and lactone (28, Fig. 7d). The actual $E_{\mathrm{A}}$ values for both intramolecular HERON reactions $\left(32 \mathrm{kcal} \mathrm{mol}^{-1}\right.$ and $39 \mathrm{kcal} \mathrm{mol}^{-1}$ ) are very similar to those for corresponding migration of acetoxyl and methoxyl from the syn form of $N$-acetoxy- $N$-methoxyacetamide $\mathbf{1 3 a}\left(34 \mathrm{kcal} \mathrm{mol}^{-1}\right.$ and $40 \mathrm{kcal} \mathrm{mol}^{-1}$ ) and, in this case, acyloxyl is again preferred by $6.7 \mathrm{kcal} \mathrm{mol}^{-1}$. Both reactions are endothermic and formation of the lactone and acyloxynitrene is much less favourable.

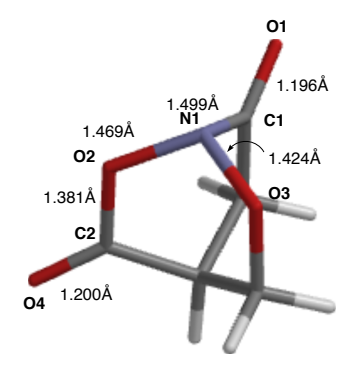

(a)

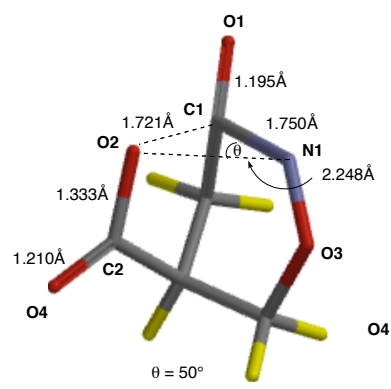

(b)

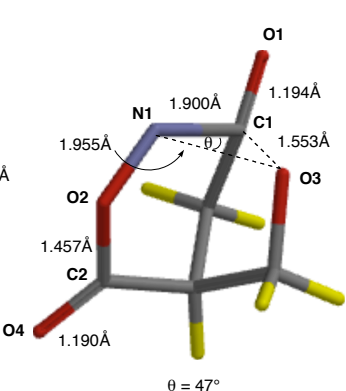

(c)

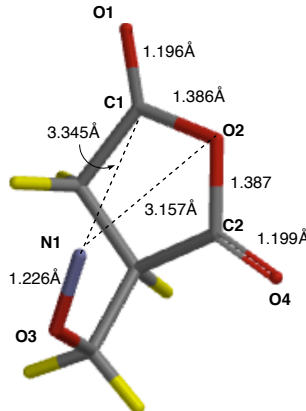

(d)

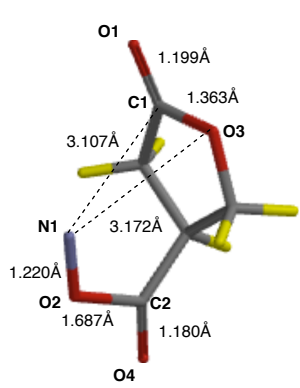

(e)

Fig. 7 B3LYP/6-31G(d) optimised structures for (a) ground state 2',2"-dioxa-2,3'-quinuclidione 19, transition states for (b) acyloxyl and (c) alkoxyl migration and relaxed transition states from (d) acyloxyl and (e) alkoxyl migration.

Only methoxyl migration from both conformers of $N$-methoxy- $N$-methylthiylacetamide $\mathbf{1 3 b}$ is viable. The overall $E_{\mathrm{A}}$ is, in both cases, similar to that for acyloxy migration in 13a but the increased resonance in this system results in lower $E_{\text {rearr }}$ values. The reduced electronegativity of sulfur facilitates the migration process relative to the oxygen destabilisation in 13a. However, it is far less effective at driving migration than nitrogen in 13c or 13f. The $\mathrm{n}_{\mathrm{S}}-\sigma^{*}{ }_{\text {NO }}$ anomeric interaction is likely to be weaker than an $n_{N}-\sigma^{*}{ }_{N O}$ effect. While the $3 p$ orbital on sulfur is higher in energy than an oxygen $2 p$ orbital which would benefit interaction with the low energy $\sigma^{*}{ }_{\text {NO }}$, its overlap with $\sigma^{*}{ }_{\mathrm{NO}}$ is likely to be weaker on account of its larger, more diffuse nature; $\mathrm{n}_{\mathrm{Y}}-\sigma_{\mathrm{NX}}^{*}$ anomeric overlap is best between $\mathrm{X}$ and $\mathrm{Y}$ orbitals of similar size. ${ }^{2,8}$ Overall, HERON reactions of $\mathrm{N}$-alkoxy- $\mathrm{N}$-alkylthiylamides would be expected at similar, high temperatures to those required for 
the formation of anhydrides from thermal decomposition of $N$-acyloxy- $N$-alkoxyamides. Since formation of $N$-alkoxy- $N$-alkylthiylamides upon reaction of thiols with $N$-acyloxy- $N$-alkoxyamides has low $E_{\mathrm{A}}$ 's of between 9 and $16 \mathrm{kcal} \mathrm{mol}^{-1}$ and occurs at measurable rates at room temperature resulting in formation of disulfides and hydroxamic esters (Scheme 6$),{ }^{18}$ the HERON reaction at these temperatures is not competitive with bimolecular scavenging of these intermediates by thiols.

Migration of methoxyl from either conformer of the carbamate $13 \mathbf{c}$ has a similar $E_{\text {rearr. }}$ to that of $N$ methoxy- $N$-dimethylaminoacetamide $13 f$. In both the carbamate $\mathbf{1 3 c}$ and the amide $\mathbf{1 3 f}$ the rearrangment is driven by the availability of a loosely bound amine lone pair of electrons, which results in a strong $n_{N}-\sigma^{*}{ }_{N O}$ anomeric interaction. Furthermore, the presence of the more electronegative methoxyl oxygen at the carbonyl in 13c, as opposed to electron donating methyl at that position in 13f, has no impact upon $E_{\text {rearr }}$. It is testament to the nature of the HERON transition state in which charge at the carbonyl carbon remains similar at the transition state (syn $\mathrm{N}$-methoxy$N$-dimethylaminoacetamide $\mathbf{1 3 f},+0.602)$ to that in the ground state $(\operatorname{syn} \mathbf{1 3 f}+0.576)$, since the $C-$ $N$ bond breaks in concert with $C-O$ bond formation in an intramolecular $\mathrm{S}_{\mathrm{N}} 2$ reaction at the carbonyl carbon. ${ }^{40,46}$ Charges at the carbonyl carbon in the carbamate ground states of 13c (anti +0.810$, syn +0.807$)$ and their rearrangement transition states ( ex anti +0.818 , ex syn +0.826$)$ are also similar.

1-Acyl-1-alkoxydiazenes, formed as intermediates in the decomposition of $N, N^{\prime}$-diacyldialkoxyhydrazines $\mathbf{3}^{23,40,44}$ or thermal decomposition of $N$-alkoxy- $N$-azidoamides $\mathbf{1 g},{ }^{5,21}$ rearrange spontaneously to esters and nitrogen at room temperature. 1-Acetyl-1-methoxydiazene 13d is predicted to rearrange concertedly to methyl acetate and nitrogen in a highly exothermic process. A very low overall $E_{\mathrm{A}}$ of just $2 \mathrm{kcal} \mathrm{mol}^{-1}$ is predicted, which correlates well the residual resonance between the aminonitrene and the carbonyl $\left(-3.5 \mathrm{kcal} \mathrm{mol}^{-1}\right)$. This resonance is forfeited upon rotation to the transition state and $E_{\text {rearr. }}$ is essentially zero for this reaction. In this amino nitrene, 
which has a singlet ground state, the amide nitrogen is strongly positively charged due to donation of the amide nitrogen lone pair to the nitrene nitrogen rather than to the carbonyl. However, in $\mathbf{1 3 d}$ there is some residual resonance stabilisation of $-3.5 \mathrm{kcal} \mathrm{mol}^{-1}$, which might well be attributed to conjugation between the $C=O$ and $N^{+}=N^{-}$pi bonds. The facile HERON process is in this case driven by the presence of a high energy, loosely bound lone pair on the nitrene nitrogen and consequent anomeric weakening of the $N-O M e$ bond (Scheme 9).

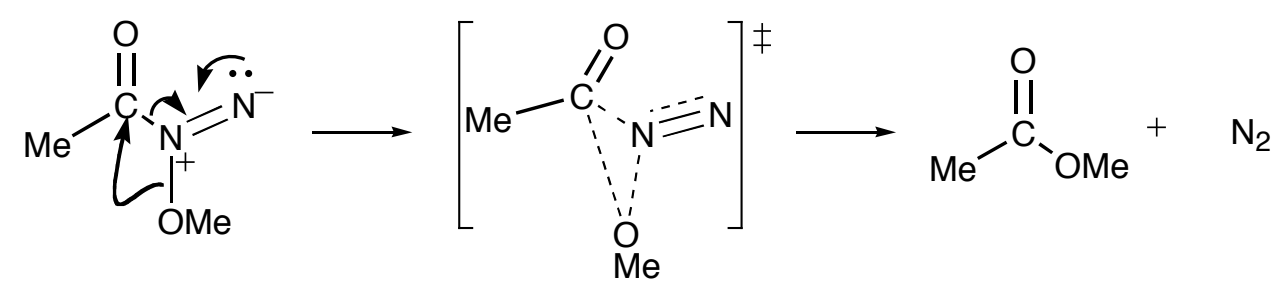

Scheme 9

$N$-Alkoxyhydroxamic acid anions also possess a high energy electron pair on the $N$-oxide and this would be expected to drive the HERON reaction. Experimentally, esters have been found to be generated intramolecularly since crossover esters are not formed in mixed reactions of $\mathrm{N}$-acyloxy$\mathrm{N}$-alkoxyamides 1a with aqueous base. ${ }^{17}$ Calculations on $N$-methoxyacetohydroxamate $13 \mathbf{e}$ predict a HERON-like process but with formation of a tetrahedral intermediate anion, which presumably generates ester and $\mathrm{NO}^{-}$in a second step. $\mathrm{HF} / 6-31 \mathrm{G}(\mathrm{d})$ calculations predict an overall $E_{\mathrm{A}}$ of 11.5 $\mathrm{kcal} \mathrm{mol}^{-1}$ but this includes resonance energy of some 6-8 $\mathrm{kcal} \mathrm{mol}^{-1}$, which results in a low $E_{\text {rearr. }}$ of approximately $4 \mathrm{kcal} \mathrm{mol}^{-1}$.

It is clear from camparison of $E_{\text {rearr. }}$ for these HERON processes, together with $E_{\text {rearr. }}$ for previouslystudied $N$-methoxy- $N$-dimethylaminoacetamide $\mathbf{1 3 f}$ and $N, N$-dimethoxyacetamide $\mathbf{1 3 g}$, that the driving force is anomeric destabilisation of the bond between the amide nitrogen and the migrating atom. More tightly bound oxygen lone pairs at $Y$ (in 13a and 13g) result in high overall activation energies but bis oxo-substitution in 13a and 13g also results in the lowest resonance energies that 
must be overcome to attain the transition state. Reduced resonance is not the overriding influence. This is reinforced by a comparison of nitrogen and oxygen systems. While the reduced combined electronegativity of nitrogen and oxygen (in $\mathbf{1 3 c}$ and 13f) results in much higher amide resonance than in systems with two oxygens, their $E_{\text {rearr. }}$ are significantly lower. Reduced sulfur electronegativity in $\mathbf{1 3 b}$ enhances amide resonance relative to $N, N$-bisoxo-substituted systems $\mathbf{1 3 a}$ and $\mathbf{1 3 g}$, but its anomeric destabilisation is similar to that of oxygen despite its higher energy lone pair. The facile reaction of the 1,1-diazene 13d is wholly the result of low resonance and a very strong anomeric interaction. The $\mathrm{HF} / 6-31 \mathrm{G}(\mathrm{d})$ derived $E_{\text {rearr. }}$ for 13e points predictably to strong destabilisation by an anion electron pair on Y. Comparing methoxyl migrations in 13a-g, $E_{\text {rearr. }}$ from Table 3 increases in the sequence $Y=N<O^{-}<N_{2} e_{2}<S M e<O M e$. Resonance energies, RE, increase in the order $\mathrm{Y}=\mathrm{N}<\mathrm{O}^{-}<\mathrm{OMe}_{\mathrm{N}}<\mathrm{NM}_{2} \sim \mathrm{SMe}$.

The nature of the migrating group $X$ in promoting the rearrangement is less clear. In the comparison of acetoxyl versus methoxyl in $\mathbf{1 3 a}$, charge transfer to the migrating oxygen should favour acetoxyl migration. However, while acetoxyl migration is preferred over methoxyl in the syn conformer and acyloxyl migration is preferred over alkoxyl migration in the tricyclic analogue 19, acetoxyl rearrangement is only marginally favoured in the anti conformer. A greater influence would be expected with strong electron donation from $Y$, and nitrogen as anomeric donor in $\mathrm{n}_{\mathrm{N}}-\sigma^{*}{ }_{\mathrm{NO}}$ interactions should lead to greater charge transfer to the migrating group. In support of this, we have shown experimentally that electron acceptor substituents at the para position of $N, N^{N}$-dibenzyloxy$N, N^{\prime}$-diacetyl hydrazines $3\left(\mathrm{R}^{2}=\mathrm{Bn}, \mathrm{R}^{1}=\mathrm{Me}\right)$ accelerate the rate of HERON rearrangement with formation of benzylacetates (Hammett $\rho=1.0) .^{40}$ No HERON transition state could be found for $N$ chloro- $N$-methoxyacetamide $\mathbf{2 5}$ and $N$-anilino- $N$-chloroacetamides $\mathbf{2 6 a}$ and $\mathbf{2 6 b}$ model systems. ${ }^{12}$ These cases resulted, instead, in heterolytic dissociation into a complex between chloride ion and methoxyl- or anilino-stabilised nitrenum ions. This would be driven by the electron affinity of 
chlorine and the resonance-stabilisation in the nitrenium ion..$^{8,29,54,55}$ Strong stabilisation of charge on $X$ can alter the preferred reaction pathway.

The role of conformation in promotion of the HERON process is three-fold. Firstly, concomitant with reduced resonance, owing to the more tightly bound amide nitrogen lone pair, the nitrogen tends towards $\mathrm{sp}^{3}$ hybridisation since increased $\mathrm{p}$ character favours transfer of electron density to the $X$ and $Y$ substituents. However, $\mathrm{sp}^{3}$ hybridisation also favours anomeric interactions since $\mathrm{n}_{\mathrm{Y}}-$ $\sigma^{*}{ }_{\mathrm{sp}_{\mathrm{Sp}} \mathrm{X}}$ p-orbital overlap integrals are better than edge-on overlap with $\mathrm{n}_{\mathrm{Y}}-\sigma^{*}{ }_{\mathrm{N}_{\mathrm{sp}}{ }^{2} \mathrm{X}}$ overlap., 8 Secondly, alignment and overlap of the $Y$ lone pair and $N X \sigma^{*}$ orbitals is essential for anomeric destabilisation of the $N-X$ bond. In 13a-c (Fig. 2) and in $\mathbf{1 3 f}{ }^{3,40,46}$ and $\mathbf{1 3 g}{ }^{1,9,11}$ conformations are adopted in the ground state structures for near ideal overlap. Conformation can actually dictate the mode of reaction. We have recently suggested that the optimal $\mathrm{n}_{\mathrm{O}_{\mathrm{exo}}}-\sigma^{*}{ }_{{ }_{\mathrm{NO}} \mathrm{endo}_{\mathrm{o}}}$ anomeric destabilisation of the endocycic $N-O$ bond in $\delta$-oxazinolactam 24 leads to preferential ring contraction rather than ring opening of $\delta$-oxazinolactam. The $\mathrm{n}_{\mathrm{O}_{\text {endo }}}-\sigma^{*}{ }_{\mathrm{NO}_{\mathrm{exo}}}$ anomeric interaction is completely switched off in the ground state structure. ${ }^{11}$ Thirdly, conformation can also impact upon the intrinsic RE of similarly substituted systems. The RE of $N, N$-dimethoxyacetamide $\mathbf{1 3 g}$ (-8.6 $\left.\mathrm{kcal} \mathrm{mol}^{-1}, \tau=9^{\circ}\right)$ and the relatively strain-free $\delta$-oxazinolactam $24\left(-8.8 \mathrm{kcal} \mathrm{mol}^{-1}, \tau=13^{\circ}\right)$ is reduced in the ground state $\gamma$-oxazinolactam $23\left(-4.8 \mathrm{kcal} \mathrm{mol}^{-1}\right)$ owing to substantial twisting about the $N-C(O)$ bond $\left(\tau=-37^{\circ}\right)$. HERON ring opening of both lactams 23 and $\mathbf{2 4}$ have a similar $E_{\text {rearr. }}$ $\left(22.4 \mathrm{kcal} \mathrm{mol}^{-1}\right.$ and $23.8 \mathrm{kcal} \mathrm{mol}^{-1}$ respectively) but there is less resonance to overcome in the twisted $\gamma$-oxazinolactam 23 thereby reducing the $E_{\mathrm{A}}$ for HERON ring-opening of $23\left(27 \mathrm{kcal} \mathrm{mol}^{-1}\right)$ relative to that for HERON opening of $\mathbf{2 4}\left(33 \mathrm{kcal} \mathrm{mol}^{-1}\right)$. 


\section{Conclusion}

The HERON reaction is peculiar to anomeric amides, amides in which the electronegative atoms adjacent to nitrogen provide the structurally important elements for the reaction, both in modifying the hybridisation at nitrogen and its resultant resonance with the amide carbonyl, and in their participation in classical anomeric interactions through the central nitrogen. Both these effects influence the ease of the HERON reaction. However, the nature of the HERON transition state, in which the lone pair on the central nitrogen resides in the amide plane and the migrating group reacts in a plane orthogonal to that plane, allows deconvolution of the overall activation energies into a resonance component $(\mathrm{RE})$ and a rearrangement component $\left(E_{\text {rearr. }}\right)$. From this, it is clear that reduced resonance itself does not promote the reaction, since with two, more electronegative oxygen atoms at nitrogen, the resonance can be as low as $50 \%$ that of $N, N$-dimethylacetamide as is the case for $N$-acetoxy- $N$-methoxyacetamide 13a and $N, N$-dimethoxyacetamide 13g. However, activation energies for their HERON reactions are high in keeping with experimental HERON anhydride formation from 1a at elevated temperatures at which there is competition with radical decomposition. The large $E_{\text {rearr. }}$ component to the $E_{\mathrm{A}}$ in these cases is clearly due to the tightlybound lone pairs on the anomeric donor atom. On balance HERON rearrangement of acyloxyl group rather than the alkoxyl group is preferential although stereochemistry may play a role. Dialkoxyamides decompose homolytically without competitive HERON reactions.

When nitrogen replaces one oxygen atom, as in $\mathbf{1 3 c}$ and $\mathbf{1 3 f}$, there is clear evidence that energetically the more accessible lone pair on nitrogen drives the rearrangement process to the extent that higher intrinsic amide resonance $(65-70 \%$ that of $N, N$-dimethylacetamide) is readily overcome and the reactions of carbamate $13 \mathbf{c}$ and, from earlier studies, $N$-methoxy- $N$ dimethylaminoacetamide $\mathbf{1 3 f}$, to give respectively dimethylcarbonate and methyl acetate together with 1,1-dimethyldiazene, have a much lower overall $E_{\mathrm{A}}$ and very low $E_{\text {rearr }}$. This is borne out of the 
strong anomeric effect and destabilisation of the bond to the migrating oxygen. The calculated barriers are entirely consistent with experimental findings

The anomeric driving force for oxygen migration when sulfur is attached to nitrogen is radically diminished and with enhanced resonance ( $70 \%$ that of $N, N$-dimethylacetamide), on account of its lower electronegativity relative to either oxygen or nitrogen, the reaction is predicted to have a high $E_{\mathrm{A}}$ and would only occur at elevated temperatures. Despite its higher energy lone pairs, sulfur, as an anomeric donor, is not as effective as nitrogen most probably on account of disparity in orbital size. Reverse migration of thiomethyl in $\mathbf{1 3 b}$ was not viable.

Two systems with high energy electron pairs on the anomeric donor atom, $\mathbf{1 3 d}$ and $\mathbf{1 3 e}$, models for 1-acyl-1-alkoxydiazenes $\mathbf{1 h}$ and $\mathrm{N}$-alkoxyhydroxamate anions $\mathbf{1 d}$ both of which undergo facile HERON reactions experimentally, rearrange with low barriers, though the hydroxamate 13d is not a true HERON reaction. $\mathbf{1 h}$ has trivial resonance energy, some $15 \%$ that of $N, N$-dimethylacetamide, and loss of this is basically the only activation energy for the reaction. The rearrangement process is extremely exothermic. It is not surprising that 1-acyl-1-alkoxydiazenes, formed from decomposition of $N$-alkoxy- $N$-azidoamides $\mathbf{1 g}$ can react to form highly hindered esters in very exothermic reactions although the intrinsic cleavage of $N-C(O)$ bonds at the HERON transition state also plays a role, obviating the formation of a highly hindered tetrahedral intermediate..$^{21}$

The nature of the migrating group and its substituents can lower $E_{\mathrm{A}}$ 's but dissociation to nitrenium ions is predicted for chlorine systems $\mathbf{2 5}$ and 26. The electronegative acyl methoxyl in carbamate 13c appears not to influence reactivity relative to the acetamide $\mathbf{1 3 f}$ in keeping with the theoretical properties of the transition state which involves concomitant $N-C(O)$ bond cleavage with the migration resulting in little change in the charge at the amide carbon. 
HERON reactivity is also influenced by conformation in at least three ways. Conformations about the $N-C(O)$ bond can reduce resonance and thereby HERON $E_{\mathrm{A}}$ 's. Conformation about $N-X$ and $N-Y$ bonds at the amide nitrogen should optimise $\mathrm{n}_{\mathrm{Y}}-\mathrm{\sigma}^{*}{ }_{\mathrm{NX}}$ interactions and pyramidality at nitrogen would be expected to facilitate anomeric overlap.

\section{Acknowledgement}

The author (SAG) greatly values his friendship with Arvi Rauk over many years and his enthusiastic interest in our early discoveries of the HERON reaction, which led to the strong theoretical basis for this novel process, as well as to our understanding of the unusual properties of anomeric amides. 


\section{References}

1. Rauk, A.; Glover, S. A. J. Org. Chem. 1996, 61, 2337.

2. Glover, S. A. Tetrahedron 1998, 54, 7229.

3. Glover, S. A.; Rauk, A. J. Org. Chem. 1999, 64, 2340.

4. Glover, S. A.; Mo, G.; Rauk, A.; Tucker, D.; Turner, P. J. Chem. Soc., Perkin Trans. 2 1999, 2053.

5. Glover, S. A.; Rauk, A. J. Chem. Soc., Perkin Trans. 2 2002, 1740.

6. Gillson, A.-M. E.; Glover, S. A.; Tucker, D. J.; Turner, P. Org. Biomol. Chem. 2003, 1, 3430.

7. Glover, S. A., $N$-Acyloxy- $N$-alkoxyamide - Structure, Properties, Reactivity and Biological Activity. In Adv. Phys. Org. Chem.; Richard, J., Ed. Elsevier: London, 2008; pp 35.

8. Glover, S. A., N-Heteroatom-substituted hydroxamic esters. In The Chemistry of Hydroxylamines, Oximes and Hydroxamic, Acids, Part 2; Rappoport, Z.; Liebman, J. F., Eds. Wiley: Chichester, 2009; pp 839.

9. Glover, S. A.; White, J. M.; Rosser, A. A.; Digianantonio, K. M. J. Org. Chem. 2011, 76, 9757.

10. Digianantonio, K. M.; Glover, S. A.; Johns, J. P.; Rosser, A. A. Org. Biomol. Chem. 2011, 9, 4116.

11. Glover, S. A.; Rosser, A. A.; Taherpour, A.; Greatrex, B. W. Aust. J. Chem. 2014, 67, 507.

12. Glover, S. A.; Rosser, A. A.; Spence, R. M. Aust. J. Chem. 2014, 67, 1344.

13. Campbell, J. J.; Glover, S. A. J. Chem. Soc., Perkin Trans. 2 1992, 1661.

14. Campbell, J. J.; Glover, S. A. J. Chem. Res. (S) 1999, 8, 474.

15. Glover, S. A. Arkivoc 2001, Part xii, Issue in Honour of O.S.Tee, ms. OT-308C, 143.

16. Cavanagh, K. L.; Glover, S. A.; Price, H. L.; Schumacher, R. R. Aust. J. Chem. 2009, 62, 700.

17. Glover, S. A.; Hammond, G. P.; Bonin, A. M. J. Org. Chem. 1998, 63, 9684. 
18. Glover, S. A.; Adams, M. Aust. J. Chem. 2011, 64, 443.

19. Campbell, J. J.; Glover, S. A.; Hammond, G. P.; Rowbottom, C. A. J. Chem. Soc., Perkin Trans. 2 1991, 2067.

20. Bonin, A. M.; Glover, S. A.; Hammond, G. P. J. Chem. Soc., Perkin Trans. 2 1994, 1173.

21. Glover, S. A.; Mo, G. J. Chem. Soc., Perkin Trans. 2 2002, 1728.

22. Bonin, A. M.; Banks, T. M.; Campbell, J. J.; Glover, S. A.; Hammond, G. P.; Prakash, A. S.; Rowbottom, C. A. Mutat.Res. 2001, 494, 115.

23. Buccigross, J. M.; Glover, S. A.; Hammond, G. P. Aust. J. Chem. 1995, 48, 353.

24. Kikugawa, Y.; Kawase, M. J. Am. Chem. Soc. 1984, 106, 5728.

25. Kikugawa, Y.; Shimada, M. Chem. Lett. 1987, 1771.

26. Kikugawa, Y.; Kawase, M.; Miyake, Y.; Sakamoto, T.; Shimada, M. Tetrahedron Lett. 1988, 29, 4297.

27. Kikugawa, Y.; Shimada, M.; Matsumoto, K. Heterocycles 1994, 37, 293.

28. Kawase, M.; Kitamura, T.; Kikugawa, Y.J. Org. Chem. 1989, 54, 3394.

29. Glover, S. A.; Goosen, A.; McCleland, C. W.; Schoonraad, J. L. J. Chem. Soc., Perkin Trans. 1 1984, 2255.

30. Glover, S. A.; Goosen, A.; McCleland, C. W.; Schoonraad, J. L. Tetrahedron 1987, 43, 2577.

31. Glover, S. A.; Rowbottom, C. A.; Scott, A. P.; Schoonraad, J. L. Tetrahedron 1990, 46, 7247.

32. Shtamburg, V. G.; Tsygankov, A. V.; Klots, E. A.; Kostyanovsky, R. G. Mendeleev Commun. 2004, 14, 208.

33. Shtamburg, V. G.; Klots, E. A.; Pleshkova, A. P.; Avramenko, V. I.; Ivonin, S. P.; Tsygankov, A. V.; Kostyanovsky, R. G. Russ. Chem. Bull. 2003, 52, 2251.

34. Shishkin, O. V.; Zubatyuk, R. I.; Shtamburg, V. G.; Tsygankov, A. V.; Klots, E. A.; Mazepa, A. V.; Kostyanovsky, R. G. Mendeleev Commun. 2006, 16, 222. 
35. Shtamburg, V. G.; Tsygankov, A. T.; Shishkin, O. V.; Zubatyuk, R. I.; Uspensky, B. V.; Shtamburg, V. V.; Mazepa, A. V.; Kostyanovsky, R. G. Mendeleev Commun. 2012, 22, 164.

36. Shtamburg, V. G.; Tsygankov, A. V.; Gerasimenko, M. V.; Shishkin, O. V.; Zubatyuk, R. I.; Mazepa, A. V.; Kostyanovsky, R. G. Mendeleev Commun. 2011, 21, 50.

37. Shtamburg, V. G.; Shishkin, O. V.; Zubatyuk, R. I.; Kravchenko, S. V.; Tsygankov, A. V.; Mazepa, A. V.; Klots, E. A.; Kostyanovsky, R. G. Mendeleev Commun. 2006, 16, 323.

38. Shtamburg, V. G.; Shishkin, O. V.; Zubatyuk, R. I.; Kravchenko, S. V.; Tsygankov, A. V.; Shtamburg, V. V.; Distanov, V. B.; Kostyanovsky, R. G. Mendeleev Commun. 2007, 17, 178.

39. Buccigross, J. M.; Glover, S. A. J. Chem. Soc., Perkin Trans. 2 1995, 595.

40. Glover, S. A.; Mo, G.; Rauk, A. Tetrahedron 1999, 55, 3413.

41. Glover, S. A.; Rauk, A.; Buccigross, J. M.; Campbell, J. J.; Hammond, G. P.; Mo, G.; Andrews, L. E.; Gillson, A.-M. E. Can. J. Chem. 2005, 83, 1492.

42. Cavanagh, K. L.; Glover, S. A. Unpublished data.

43. Johns, J. P.; van Losenoord, A.; Mary, C.; Garcia, P.; Pankhurst, D. S.; Rosser, A. A.; Glover, S. A. Aust. J. Chem. 2010, 63, 1717.

44. De Almeida, M. V.; Barton, D. H. R.; Bytheway, I.; Ferriera, J. A.; Hall, M. B.; Liu, W.; Taylor, D. K.; Thomson, L. J. Am. Chem. Soc. 1995, 117, 4870.

45. Thomson, L. M.; Hall, M. B. J. Phys. Chem. A 2000, 104, 6247.

46. Glover, S. A.; Rosser, A. A. J. Phys. Org. Chem. 2015, 28, 215.

47. Glover, S. A.; Rosser, A. A. J. Org. Chem. 2012, 77, 5492.

48. Greenberg, A., The Amide Linkage as a Ligand: Its Properties and the Role of Distortion. In The Amide Linkage. Structural Significance in Chemistry, Biochemistry and Materials Science; Greenberg, A.; Breneman, C. M.; Liebman, J. F., Eds. John Wiley \& Sons, Inc.: New York, 2003; pp 47.

49. Greenberg, A.; Moore, D. T.; DuBois, T. D. J. Am. Chem. Soc. 1996, 118, 8658. 
50. Greenberg, A.; Venanzi, C. A. J.Am. Chem. Soc. 1993, 115, 6951.

51. Spartan10 for Macintosh, 1.1.0; Wavefunction inc.: Irvine, CA, 2010.

52. Dunitz, J. D., X-Ray Analysis and Structure of Organic Molecules. Cornell University Press: London, 1979.

53. Winkler, F. K.; Dunitz, J. D. J. Mol. Biol. 1971, 59, 169.

54. Glover, S. A.; Scott, A. P. Tetrahedron 1989, 45, 1763.

55. Schroder, D.; Grandinetti, F.; Hrusak, J.; Schwarz, H. J. Phys. Chem. 1992, 96, 4841. 


\section{Figure Captions:}

Fig. 1. Theoretically derived transition state for the generalised HERON reaction of an $X, Y$ substituted amide; (a) perspective drawing, (b) Newman projection along the $N-C(O)$ bond.

Fig. 2. Lowest energy ground state structures for 13a-d (at B3LYP/6-31G(d)) and 13e (at HF/6$31 \mathrm{G}(\mathrm{d})) ; \chi$ and $\tau$ are the Winkler-Dunitz pyramidality and twist indices; average angles at nitrogen are denoted by $<>$.

Fig. 3. B3LYP/6-31G(d) optimised transition states for migration of acetoxyl from (a) syn and (b) anti conformers of $N$-acetoxy- $N$-methoxyacetamide 13a and migration of methoxyl from (c) anti and (d) syn conformers of $N$-acetoxy- $N$-methoxyacetamide 13a.

Fig. 4. B3LYP/6-31G(d) optimised transition states for migration of methoxyl from (a) syn and (b) anti conformers of $N$-methoxy- $N$-methylthiylacetamide $\mathbf{1 3 b}$ and migration of methoxyl from (c) syn and (d) anti conformers of $N$-methoxy- $N$-dimethylamino- $O$-methylcarbonate $\mathbf{1 3 c}$.

Fig. 5. (a) B3LYP/6-31G(d) optimised transition state for migration of methoxyl in 1-acetyl-1methoxydiazene 13d and (b) HF/6-31G(d) optimised transition state for migration of methoxyl in $N$-methoxyacetohydroxamate $\mathbf{1 3 e .}$

Fig. 6. Products and product complexes from relaxation of lowest energy transition states for HERON reactions of 13a-e transition states. 
Fig. 7. B3LYP/6-31G(d) optimised structures for (a) ground state 2 ',2"-dioxa-2,3'-quinuclidione 19, transition states for (b) acyloxyl and (c) alkoxyl migration and relaxed transition states from (d) acyloxyl and (e) alkoxyl migration. 